Portland State University

PDXScholar

Winter 3-11-2016

\title{
Women as Transformational Leaders: Learning to Lead in the Community College
}

Jennifer R. Grove-Heuser

Portland State University

Follow this and additional works at: https://pdxscholar.library.pdx.edu/open_access_etds

Part of the Community College Leadership Commons, Educational Leadership Commons, and the Women's Studies Commons

Let us know how access to this document benefits you.

\section{Recommended Citation}

Grove-Heuser, Jennifer R., "Women as Transformational Leaders: Learning to Lead in the Community College" (2016). Dissertations and Theses. Paper 2706.

https://doi.org/10.15760/etd.2702

This Dissertation is brought to you for free and open access. It has been accepted for inclusion in Dissertations and Theses by an authorized administrator of PDXScholar. Please contact us if we can make this document more accessible: pdxscholar@pdx.edu. 
Women as Transformational Leaders: Learning to Lead in the Community College

$$
\text { by }
$$

Jennifer R. Grove-Heuser

A dissertation submitted in partial fulfillment of the requirements for the degree of

\section{Doctor of Education}

in

Educational Leadership: Curriculum and Instruction

Dissertation Committee:

Micki M. Caskey, Chair

Dannelle Stevens

Karen Haley

Leslie McBride

Portland State University

2016 
(C) 2016 Jennifer R. Grove-Heuser 


\begin{abstract}
Community colleges face a growing crisis in leadership and a critical aspect of this crisis is a shortage of leaders. The representation of women leaders in community colleges has increased more than other sector of higher education. This upswing suggests that community colleges are the most likely place for women to achieve executive leadership status. Yet, community college history is grounded in male dominance and women leaders remain marginalized in the community college system. The purpose of my study was to examine some of the factors that contribute to women executive leaders' success specifically: (a) how women experience their leadership role in the community college, (b) how women vice presidents use transformational leadership, and (c) how women administrative vice presidents have learned to lead. In the literature review, I considered leadership, the community college, organizational culture, women's development and learning.

The research approach for this study was an exploratory case study design. The participants were female Vice Presidents in community colleges within the Western United States. To answer research questions about the participants' perspectives on leadership in the community college, use of transformational leadership practices, and learning to lead, I used a survey instrument and conducted interviews. By exploring factors that contribute to the success of women executive leaders, one intention of this study was to arm institutions with information to support the development of women leaders as efforts focus on addressing the leadership crisis, and inform aspiring women leaders while they make their ascent to the executive leadership ranks.
\end{abstract}




\section{DEDICATION}

I dedicate my dissertation to women leaders past, present and future. Because, "we're women, and we take care of one another" - study participant. 


\section{ACKNOWLEDGMENTS}

I want to thank my family. I thank my husband for his support and wise words, especially as we experience the joys and wonders of early parenthood together. I thank my daughter for her incandescent enthusiasm for life, curiosity, and love of learningthese are just a few of the many qualities I admire and cherish about her. I thank my parents who have seen me through it all, truly. I thank my mom, the first in her family to go to college and graduate school, an accomplished educator herself, and most of all for her unwavering faith throughout my journey — there are no words. I thank my dad; his steady work ethic, inquisitive and analytic mind have been an inspiring and treasured influence in my life. I want to acknowledge all the women in my family, each of whom brings their own special strength, power, and love, to hold up our half of the sky.

My friends have been a source of encouragement and understanding for me. They listened to my challenges and discoveries with a caring heart.

The women leaders who gave generously of their time to share their stories, only with their insightful reflections was this research possible.

With genuine gratitude, I thank my committee for their comments, questions, and high standards: Micki M. Caskey, Ph.D., Chair, Dannelle Stevens, Ph.D., Karen Haley, Ed.D. and Leslie McBride, Ph.D.

My deepest thanks to my advisor, professor, colleague, friend, and guiding light, Micki Caskey, Ph.D. I admire her intellect, scholarship and resilience and thank her for her countless hours of reading, review, and feedback. I have learned from the best. 
Table of Contents

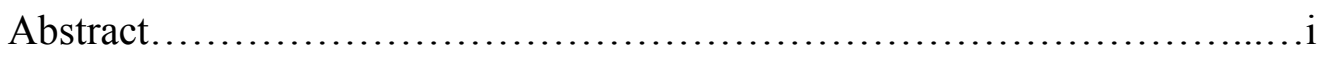

Dedication.......................................................

Acknowledgments................................................ii

List of Tables.....................................................

List of Figures................................................ viii

Chapter 1: Introduction.............................................

Statement of the Problem.............................................

Purpose........................................................6

Research Questions..........................................

Chapter 2: Review of the Literature................................... 9

Theoretical Framework......................................... 10

Criticisms of Transformational Leadership Theory....................15

Leadership.................................................16

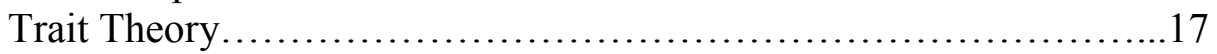

Behavioral..................................................... 18

Contingency....................................................

Contextual.................................................... 19

Transformational and Transactional................................20

Relational....................................................... 21

Feminine Principles...........................................22

The Community College Milieu..................................23

Organizational Culture and Leadership.............................26

The Role of Gender in Leadership.................................30

Women's Development......................................... 35

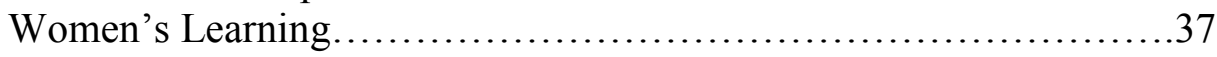

Summary of Literature Review..............................43

Chapter 3: Methods..................................................44

Research Questions.........................................45

Research Perspective............................................45

Participants.................................................47

Limitations................................................... 48

Data Collection Procedures......................................49

Instrumentation.................................................51

Demographic Survey........................................52

Interview Protocol.............................................52 
Leadership Practices Inventory....................................53

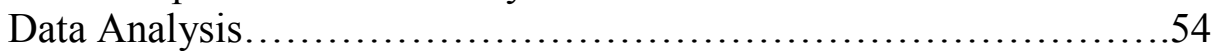

Role of the Researcher.............................................56

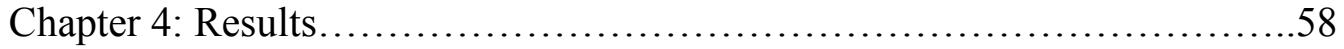

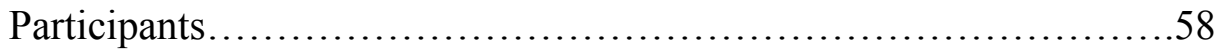

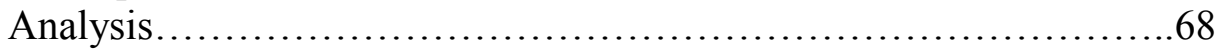

Results by Research Question........................................71

Women Vice Presidents' Leadership Experiences......................71

Gender Culture.................................................72

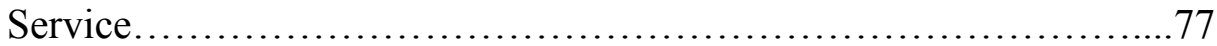

Quality of Leadership Connection.................................80

Vice Presidents and Transformational Leadership....................83

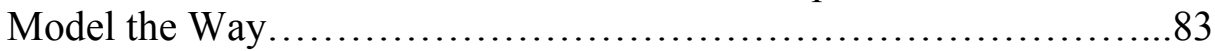

Inspire a Shared Vision.......................................... 85

Challenge the Process............................................... 86

Enable Others to Act........................................... 88

Learning the Lead in the Community College...........................93

Mentoring...................................................... 94

Leadership Observation.......................................96

Accepting Additional Duties.........................................98

Networking....................................................... 99

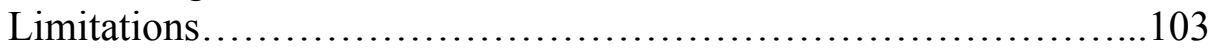

Assumptions................................................. 103

Researcher's Perspective.............................................103

Limits of the Study and Analysis...................................104

Summary or Results..........................................106

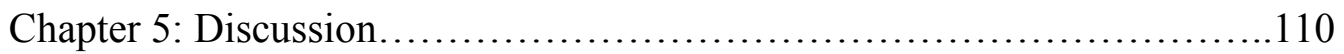

Statement of the Problem...................................... 110

Purpose of the Study ........................................... 110

Research Questions and Methodology.............................111

Synthesis and Findings..........................................111

Implications......................................................

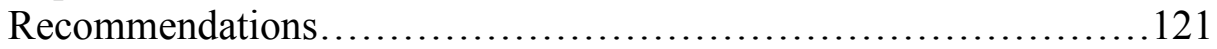

Further Study ............................................... 122

Community College .............................................122

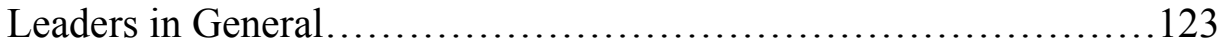

Current and Aspiring Leaders....................................124

References........................................................ 126 
Appendices

A. Informed Consent.......................................142
B. Women Administrative Vice Presidents Demographic survey.....143
C. Women Administrative Vice Presidents Interview Questions.....144
D. Kouzes and Posner's Leadership Practices Inventory.............145 
List of Tables

Table 1. Data Analysis of Research Results.......................................51 
List of Figures

Figure 1. Research Question Flowchart ....................................... 70 


\section{CHAPTER 1: INTRODUCTION}

In this dissertation, I describe a study to examine women's leadership practices and their experience as leaders in the community college from a transformational leadership perspective. In the introduction, I provide the background and the purpose for this inquiry. In the second chapter, I present a review of the literature, research questions, and the significance of this study, followed by a description of the research methodology in chapter three. In the final chapters, I report the results and offer recommendations for policy and future study.

\section{Statement of the Problem}

Community colleges have the highest percentage of women leaders of all sectors within higher education (Valdata, 2006) however; these women are still marginalized as leaders (Townsend \& Twombly, 2007). Underlying this issue is an aging cohort of leaders, both men and women that continues to feed the leadership crisis.

\section{The Issue}

Community colleges face a growing crisis in leadership. Surrounding this crisis are strong influences that shape the current milieu of higher education including instructional delivery (Lofstrom \& Nevgi, 2007; Moore \& Burton, 1998), a paradigm shift to a learning centered model (Barr \& Tagg, 1995), reduced funding (Katsinas, Tollefson, \& Reamey, 2008), and changing demographics (Haley, 2001).

Despite cultural diversity being greater in the community college student body than in any other sector of higher education (Williams, 2002), there has been little change in the diversity of chief academic officers from 1985 to 2000 (Amey, VanDerLinden, \& Brown, 2002). The overall number of community college leaders has also been shrinking 
(American Association of Community Colleges [AACC], 2012a). Executive leaders are typically those leaders that serve on an executive cabinet and have the title of vice president. In a recent survey, $75 \%$ of respondents reported that they would retire in 10 years and $43 \%$ in the next five years, reinforcing the concern of an aging cohort of executive leaders. In 2012, the median age of community college presidents was 60 years of age (AACC, 2012b). Senior leadership positions that feed the pool of candidates for the presidency have also slowed (Amey et al., 2002).

Several problems feed this crisis in leadership including low enrollment in community college leadership programs and low levels of diversity in the applicant pool (Evelyn, 2001). Low diversity in the applicant pool makes it difficult to develop leaders who reflect and represent the perspectives and interests of a diverse student body. In this dissertation, I focus on women because they are marginalized as leaders in the community college system (Townsend \& Twombly, 2007). The number of women leaders does not reflect the student body and this imbalance is even more apparent for women of color.

Opportunities that existed for women faculty in the community college during the 1960s did not exist for women in positions of executive leadership. Nevertheless, gains were visible from 1986-1998 when women in leadership positions jumped from $8 \%$ to $22 \%$ (Phillippe, 2000). In 2002, the number of women leaders reached 27\% (Valdata, 2006), higher than any other sector of higher education. This increase would appear to make community colleges the most likely place for women to attain executive leadership positions within higher education (Townsend \& Twombly, 2007). 
Understanding how women leaders succeed can educate emerging leaders and inform institutions on supportive practices. The focus on women executive leaders in the Western United States may provide regional insight. To support the developmental process of women leaders and the institutions in which they lead is an attractive pursuit personally and professionally. Strides made in this endeavor possess the potential to affect the leadership shortage within the broader context of higher education as a whole. By definition, this sector of higher education claims to be responsive to community needs through open access, low tuition, and a professed value of equality. Research on women's experiences within the community college climate has focused more often on faculty and less on leaders (Townsend \& Twombly, 2007). This study helps address the gap in the research literature about women's leadership experiences within the sector of higher education hosting the greatest number of women leaders.

Community colleges are public and private institutions of higher learning that grant associate's degrees, offer certificate-training programs, vocational, and continuing education; and prepare students for bachelor degree programs at four-year institutions. The development of community colleges became a priority in 1947 because of the Truman Commission (AACC, 2012b). Following World War II and the creation of the GI Bill, the demand for institutions of higher education increased dramatically. Commonly referred to as the people's colleges, open-door colleges and democracy's colleges, the community college numbers peaked during the 1960 s to more than 450 (Cohen \& Florence, 1996). The community college is one of the friendliest of all institutions within higher education especially for marginalized groups (Outcalt, 2002; Townsend \& Twombly, 1998). Community colleges are an American invention, 
beginning with Joliet Junior College, the first pubic community college established in 1901 (Joliet Junior College, n.d.). These institutions educate over half of the undergraduates in the United States (AACC, 2012b).

Nationwide, there are 1,123 community colleges (AACC, 2015). The students they serve balance a heavy load. Most, $62 \%$ of full time students attending community college work part time or full time. These colleges are an important gateway for vulnerable populations, with $36 \%$ of it students being first generation college students and $17 \%$ being single parents. Affordability is a key attraction to these colleges as annual tuition is on average, one third that of four-year institutions, $\$ 3,347$ and $\$ 9,139$ respectively. Not well known is the fact that $25 \%$ of the community colleges in the United States have campus housing. These institutions granted 750,394 associates degrees in 2012-2013 (AACC, 2015).

As summarized by one Northwestern institution, the goals of two-year colleges are threefold: (a) to meet economic demand- "Strengthen state and local economies by meeting the demands for a well-educated and skilled workforce;" (b) to promote student success - “Achieve increased educational attainment for all residents across the state;" and (c) inspire innovation "Use technology, collaboration and innovation to meet the demands of the economy and improve student success" (Washington State Board for Community and Technical Colleges, 2015a). Community colleges play a vital role in the higher education delivery system, through their open access design, basic skills, English language, transfer education, and workforce development. They are the workhorse for almost half of the undergraduates in the United States. In one state in the region, community colleges served over 471,000 students in 2008-2009. In the most recent 
economic downturn, community colleges nationally were forced to reduce per student spending by 3.4\%, a higher cut than any other sector of higher education (Delta Cost Project, 2009). Even though these institutions withstand the worst of cuts in funding, one Northwest community college system provided 15,135 students with worker retraining, a rise of $36 \%$. These colleges provide over $95 \%$ of all adult literacy education, are a primary source for first generation students, and are the entry point for $41 \%$ of students receiving bachelor's degrees. In 2009, four colleges piloted a bachelor degree-granting program (Washington State Board for Community and Technical Colleges, 2015b).

Affordability is an increasing concern for those seeking higher education, colleges in one Northwestern state supported almost 12,000 high school students in a dual enrollment program that allowing high school students to earn an associate's degree while simultaneously completing their high school diploma. This program offered substantial cost savings through supplemental tuition as well as indirect savings through a reduction in the time undergraduates spent completing their degree.

Despite the perceived openness of the community college within the whole of higher education, its history is grounded in male dominance (Outcalt, 2002; Townsend \& Twombly, 1998). Men hold the majority of leadership positions in the community college, historically and presently (Chliwniak, 1997), so scholars consider these organizations to be male-centered. Leadership terminology and theory have been based on the stereotypical male experience (Miner, 1993). Consequently, "leadership has been studied using male norms as the standard for behavior" (Chliwniak, 1997, p. 5).

Townsend and Twombly (2007) asserted: 
The community college is a gendered institution whose practices have not always served and do not currently serve women as well as they could and should be served, given the institution's societal mission and the proportion of women students, faculty, and presidents. (p. 215)

This line of research suggests that a cold campus climate for women, disparities in salaries, and poor representation of women leadership are still prevalent (Townsend \& Twombly, 1998).

\section{Purpose}

The purpose of this study was threefold, to understand (a) how women experience their leadership role in the community college, (b) how women vice presidents use transformational leadership, and (c) how women administrative vice presidents have learned to lead. Research from this perspective may serve to inform aspiring women leaders, provide institutions with strategies to support the development of women leaders, and address the leadership shortage in community colleges. In the midst of this leadership crisis and within the most welcoming sector of higher education for women and marginalized populations, the disparity in numbers is stunning. More than half of college students are women, yet, only $29 \%$ of community college presidents are women (Kampel, 2010) with just 13\% of those from marginalized groups (Amey \& VanDerLinden, 2002). These statistics are an improvement in comparison to all institutional classifications within higher education where only $22 \%$ of presidents are women (Kampel, 2010). Further investigation of how women have made their ascent is critical to affect change from the inside.

For this research study, leadership is defined as behaviors and actions that place focus on relationships between the leader and their constituents and assist members in 
developing a sense of common purpose (Clark, Caffarella, \& Ingram, 1998). The expectation is that the common purpose will result in a shared vision for the organization's future and subsequent organizational change, and is further identified by (Clark et al., 1998) as transformational leadership. To investigate how women in community college executive leadership positions experience their leadership, I used a case study design drawing primarily from the qualitative tradition.

\section{Research Questions}

To guide this study about women leaders in the community college, I posed the following research questions:

1. How do women experience leadership in administrative vice president positions in community colleges?

2. How do women in administrative vice president positions self-report use of transformational leadership practices?

3. How have women administrative vice presidents in the community college learned to lead?

As the leadership crisis in higher education forges onward with the number of community college leaders shrinking (AACC, 2012a), and the continued prominence of an engendered leadership culture (Chliwniak, 1997; Outcalt, 2002; Townsend \& Twombly, 1998), understanding how women lead poses a powerful potential. Findings from this research study could educate emerging leaders, institutions, and provide insight into institutional culture that may buoy solutions based thinking. As some researchers have noted, the professional advancement of women leaders in the community college

must move beyond an assessment of only numbers and critically inspect a cultural shift in 
organizational culture (Tedrow \& Rhoads, 1998; Townsend \& Twombly, 1998).

According to Martin Luther King, Jr., "Our goal is to create a beloved community and this will require a qualitative change in our souls as well as a quantitative change in our lives" (King \& Washington, 1986, p. 58). 


\section{CHAPTER 2: LITERATURE REVIEW}

In this chapter, I discuss foundational knowledge related to the study of women's leadership. A scan of the literature on leadership suggests interest in the subject remains robust and reveals studies from a multitude of disciplines including business, management, politics, healthcare, history, and education. The first section of the chapter presents the conceptual framework for the research study. The transformational leadership theory proposed in Kouzes and Posner's (2003a) Leadership Practices Inventory informs the perspective of this research study.

In the second section, I offer a summary of leadership in the literature beginning with the great-men theory and then trait theory leadership, which focuses on leaders' distinctive characteristics or personality traits. Next, I describe theories of behavioral leadership that emerged in the 1950s. Subsequently, I contrast transformational and transactional leadership. Transformational and transactional leadership types are often explained in the literature on leadership to highlight differences between leadership and management. In the last leadership category, I discuss is the concept of relational leadership. An overview of relational leadership considers more closely the power dynamic of relationships and may include descriptors like collaborative or inspiring.

In the third section of this chapter, I discuss the community college milieu including leadership competencies proposed by the American Association of Community Colleges (AACC) and the influence of the learning centered college. Organizational culture and legitimacy theory are important concepts to consider in the evaluation of women leaders' experience and ways in which they navigate institutional culture. Ways women lead as it relates to gender role expectations are outlined briefly in the section on 
gender roles in leadership. Last, to guide the inquiry of how women learn to lead, a review of women's development and women's learning is provided along with an overview of different epistemological positions.

Themes that create the backdrop for this study are (a) leadership, (b) organizational culture, (c) the role of gender, (d) women's learning and development, and (e) challenges women face in the milieu of higher education.

\section{Theoretical Framework: Transformational Leadership}

To create a frame of reference for the examination of data obtained from study participants, I used Kouzes and Posner's (2003a) transformational leadership model. Kouzes and Posner (2003a) asserted, "The mastery of the art of leadership is the mastery of the self. Leadership development is self-development" (p. vi).

According to Bass (1999), transformational leaders operate in a unique role as a role model, who inspire and operate with a high level of integrity. They stimulate followers and the organization to operate at their potential, reward performance, and foster trust and belonging. The leadership challenges facing the community college, both in depth and breadth are substantial and in a state of crisis. A significant problem often requires a powerful solution. The transformational leadership approach calls on all members, leaders, and followers to engage with deep commitment to the work. This perspective re-frames the problem and solution, personalizing it to lay a course for change that begins with intrinsic motivation. People who operate from a place of intrinsic motivation demonstrate more interest, enthusiasm, and confidence, which leads

to persistence, creativity and improved performance (Ryan \& Deci, 2000). These factors 
make transformational leadership a potent instrument for leaders and force for institutional change.

Many elements of transformational leadership such as the role of relationships, gender, learning, the community college's value of inclusion, and intrinsic motivation factor are pertinent to this study of women leaders. While I considered other leadership perspectives, I dismissed them for a variety of reasons. For example, transactional leadership relies on a give and take exchange and uses rewards and punishment to manage performance (Kellerman \& Rhode 2007). This type of leadership is more impersonal, and lacks the energy and influence necessary for organizational change (Burns, 1978), making it a poor fit to examine women leaders and the role of relationships amidst the looming weight of the leadership crisis. Another approach, trait theory emphasizes the inherent skills and capacity of the individual leader (Stogdill, 1948), heavily sided to the leader, and does not incorporate the role of relationships and misses the collaborative spirit of the community college. Similarly, behavioral leadership theory active in the 1950s and 1960s and grounded in behaviorism focuses on the actions of the leader. An aspect of this approach is the two-factor description of the degree to which a leader is friendly and supportive toward their subordinates and how leaders structure and define roles, known respectively as consideration and initiating structure (Hemphill \& Coons, 1957). It differs from trait theory in that it incorporates a learning component, a crucial aspect of my study. Yet, other theories align more closely with the factors considered necessary for a study of women leaders.

Participatory leadership is another approach considered for this study. One example of participatory leadership is Bergmann, Hurson, and Russ-Eft's (1999) 
grassroots model, which encompasses a network of members as opposed to the traditional top down organizational structure. Their model uses the acronym, CLIMB, to represent five strategies: create a compelling future, let the customer drive the organization, involve every mind, manage work horizontally, and build personal credibility. One shared strength and weakness of participatory leadership is the added engagement that can be realized when all members contribute; but the consultative approach to shared decision making can leave followers vulnerable to cynicism when leaders fail to follow through with recommended actions. The participatory leadership model is not an ideal fit for this study as the participants, Vice Presidents of Administrative Services, are responsible and ultimately accountable for public funds, compliance, policy, and safety.

The transformational leadership model is an appropriate theoretical framework for this study of women leaders in the community college. Leadership is gendered (Eagly \& Johannesen-Schmidt, 2001). Some research has demonstrated that transformational leadership practices may hold advantages for women leaders specifically because of its androgynous features (Yoder, 2001). Relationships are a central theme in women's development (Gilligan, 1993; Helgesen, 1990) and a prominent feature in transformational leadership, creating a parallel worthy of further exploration. With the role of gender ever-present in the leadership lives of women, studying how they lead successfully is essential to understanding their contributions in both the present and the future, and is especially relevant in the context of the leadership crisis.

One of the primary purposes of this study is to gain new insight into how women learn leadership. Guided by the idea that a direct relationship exists between leading and learning, Kouzes and Posner (2007) interviewed more 75,000 people. From this 
intensive body of work, Kouzes and Posner suggested that leadership is a set of behaviors and practices with the implication that leadership is learnable.

The community college setting itself is a good match to support the use of transformational leadership practices; the professed value of equity, the comparatively higher number of women in leadership and the call for change by the AACC are of few examples to this point. Evidence suggests that transformational leadership is most suitable during periods of birth, growth, and revitalization (Baglia \& Hunt, 1988). The leadership crisis in the community college and the efforts to address it are experiencing growth and revitalization.

Kouzes and Posner (2003a) described transformational leadership behaviors and practices that are learnable and reflect some key elements of the transformational leadership concept. Transformational leaders are defined by their influence on followers. They inspire trust, connection, respect, and commitment, moving performance to the highest level of potential. One frequently cited transformational leadership theorist, Bernard Bass (1996), described a focus on the needs of the individual, and includes actions that stimulate intellectual engagement of the followers on behalf of the leader, even to the extent that the leader serves as teacher. Bass's focus on the individual follower's development ultimately moves the follower to transcend beyond personal selfinterest to work in an expanded capacity on behalf of the organization. Inspiration plays a role by creating meaning for work tasks that are linked to a larger goal. The experience according to Bass, can result in an almost idealized leader but one that genuinely models traits of honesty, trust, and pride. The transformational leadership model by Kouzes and Posner (2003b) identified five practices that represent personal best leadership practices 
and are reflected in the Leadership Practices Inventory (LPI -SELF) instrument. The

best leadership practices, broadly acknowledged in the research (Taylor, 2002) are:

1. Model the way. Leaders go first. Credibility is built when people do what they say they will do. Leaders clarify their values and are authentic in the expression of those values. They build consensus based on common principles and align their "personal actions with shared values." They build commitment and momentum through daily, regular demonstration in their behavior as agents of the cause. They show through action how people should be treated and the manner in which goals should be pursued (Kouzes \& Posner, 2003b, pp. 4-5).

2. Inspire a shared vision. Leaders are passionate; they create an exciting vision for the future, then they enlist others to engage in the pursuit through shared aspirations. They bring the group together and foster commitment to the team in pursuit of a common goal. They inspire others with a hopeful vision of the future and an energized view of the organization's potential.

3. Challenge the process. Through risk taking that regularly generates small wins leaders demonstrate courage in the face of challenge. They demonstrate initiative and seek opportunities to improve and change the status quo. They question current practice to generate and/or implement new ideas and practices and are bold experimenters in pursuing opportunities to challenge the status quo. They weather mistakes as part of the learning process and learn from errors.

4. Enable others to act. By working together, establishing relationships and building trust, leaders create a sense of shared circumstances or team mentality. They empower others to act, feel capable, and reach their full potential. They value trust and respect of each member that lays a foundation of confidence in one another's work, to experience shared power. Their actions support and strengthen others to take action that results in improved competence.

5. Encourage the heart. Leaders strive to inspire hope they celebrate the excellent contributions of others, and display genuinely caring deeds. They show a high level of performance as leaders and encourage high performance from others. They recognize and reward excellent job performance. Through these actions, leaders build a strong sense of community.

Understanding how leaders learn to lead is another important aspect of this study. Kouzes and Posner (2003b) studied the process of learning leadership and identified the three major paths to learning leadership or the three Es: experience, example, and education.

The process of learning is a means of self-development (Knowles, 1980). How women learn is important to understanding their developmental process as leaders. 
According to Hayes and Flannery (2000), women's learning is diverse with relationships and interactions as a core theme. To explore how women learn leadership, I use Kouzes and Posner's (2003) three Es of learning as a foundation for interview questions.

The three Es of learning are:

1. Experience: Learning through trial and error. The most mentioned method for learning leadership is practice. Experience is cited twice as often as the next most common method of Examples, according to Kouzes and Posner (2003a). Opportunities to facilitate team meetings, chair a conference, or lead a special task force are valued lessons to learn from including both successes and failures.

2. Example: Learning by observing others. The behavior of others can be crucial experiences for growth and development in learning leadership. Role modeling and watching others handle challenging situations can trigger critical thinking on leadership strategies. Even, unfortunate circumstances such as a boss with poor leadership skills can present an opportunity of what not to do. Peers are another source of information and skill when they act in a role of advisor or counselor offering feedback on personal style and testing alternatives.

3. Education: Learning through training and coursework. Formal training can speed the process of acquiring new skills by offering multiple opportunities for practice. In a safe environment, students can challenge assumptions and methods, connect ideas, and move more quickly through test flights, sparing their constituents some of the growth pains of leadership development. (pp. 7-11)

\section{Criticisms of Transformational Leadership Theory}

Transformational leadership theory has been criticized for its presumption of purity with regard to intent. With such a powerful and persuasive tool at the hands of a leader, some theorists warn of the potential for abuse of power (Graham, 1991; Hall, Johnson, Wysocki, \& Kepner, 2002; Yukl, 1991). Strong emotions are an operative instrument in the application and success of transformational leadership in practice. As such, the question of morality and motive is pertinent. For example, few argue that Hitler transformed Germany. Narcissism, corruption, dictatorship, and the oppression of minority groups are all possible and probably enhanced with the effective use of transformational leadership, in the absence of morality. However, one might also reason 
that a truly transformational process is inherent of high morals, honesty, and fairness. Nevertheless, much of the core concepts associate with the application of transformational leadership theory have the potential to be misused.

Despite the widespread use of Kouzes and Posner's (2003a) leadership inventory and the translation of the text into 12 languages, they have acknowledged some of the best practice concepts may not be applicable across cultures. For example, recognizing and celebrating accomplishments (i.e., encouraging the heart), may not be a value that translates equally to all cultures.

\section{Leadership}

Numerous studies and exhaustive reviews of leadership have been conducted (Stogdill, 1948). Some of the earliest research on leadership proposed a great-men theory. An underlying assumption of the great men theory was that "to be a good leader one must be male and born to greatness" (Curry, 2000, p. 10). This perspective was inclusive of social context in the making of a great leader in that "the great leader must be born at the right moment in history in order for his leadership and greatness to be appreciated" (Curry, 2000, p. 10). The great men theory included many analyses of

political or military leaders' biographies. Frequently, greatness was assigned posthumously with examples of these types of leaders being George Washington and Harry Truman. Curry (2000) noted that the value of this model is related to its social context with the absence of women leaders and leaders of color. In Pathways to Leadership in Education Maxine Greene wrote in the forward about women in power:

Women struggling to construct themselves as leaders have to cope with popular images of vulnerability, self-mastery, and a distinctively male confidence... Not only do would-be women leaders have to cope with the persistent images of male 
dominance, the only professional literature available to the women trying to master what is demanded of contemporary leadership consists largely of information gathered by male policy-makers, presumed experts in theories of leadership, and male administrators. (Curry, 2000, p. ix)

The idea that leadership is more often identified as a male quality still holds true according the Schein (2001). The notion of male dominated leadership permeates popular culture as well—in the Washington Post's “Top Ten Leadership Books of All Time," nine of the books are written by men (Useem, 2009). Only the eighth book was written by a woman, Annette Simmons (2002), The Story Factor: Inspiration, Influence and Persuasion through the Art of Story Telling. With a palpable presence of the male experience consistent in the literature inside and outside of academia, the foundation for leadership theory clearly lacks the female perspective.

\section{Trait Theory}

In the earlier part of the $20^{\text {th }}$ century, trait theory was the popular approach to understanding leadership. "Leadership trait theory attempts to explain distinctive characteristics in leader effectiveness through the identification of a set of personal traits. It was assumed that potential leaders could be identified by observing and identifying personality traits" (Goff, 2003, p. 3). These traits could be developed and fine-tuned but must be inherent in the personality of the individual. Stogdill's (1948) review of 124 studies produced five leadership trait categories: (a) capacity, (b) achievement, (c) responsibility, (d) participation, and (e) status. Like the great-men theory, trait theory was one-way from leader to follower with emphasis placed on the side of the leader (Stogdill, 1948). Many lists of individual characteristics were gleaned from this early research, but consensus on the traits themselves was not clear nor did the traits appear to 
be transferable or applicable from one situation to another (Short \& Greer, 2002).

Stogdill's findings were critical in disproving trait theory:

Leadership is not a matter of passive status, or of mere possession of some combination of traits. It appears rather to be a working relationship among members of a group, in which the leader acquires status through active participation and demonstration of his capacity for carrying cooperative tasks through completion. (p. 66)

\section{Behavioral}

Trait theory faded in popularity and was replaced by behavioral leadership theory in the 1950s and 1960s (Goff, 2003; Zaccaro, 2007). Behavioral leadership theory is rooted in behaviorism and centers on the actions of the leader. Unlike trait theory, behavioral leadership theory presumes that behaviors can be learned — an important aspect of this study. Behavioral leadership theory constitutes the greatest volume of research on leadership (Ayman \& Korabik, 2010).

A series of leadership studies were conducted by the Personnel Research Board and directed by Carroll L. Shartle at Ohio State University in the 1950s that are considered significant in the formation of the behavioral approach (Halpin, 1957, Short \& Greer, 2002). Out of this work came the Leader Behavior Description Questionnaire (LBDQ) developed by Hemphill and Coons (1957). The LBDQ instrument measures the follower's perceptions of their leader. Two critical behaviors are identified in the LBDQ; they are consideration and initiating structure. Hemphill and Coons defined consideration as the extent to which a leader behaves in a support and friendly manner degree toward their subordinates. They also specified that initiating structure as the extent to which leaders structure and define their role as leaders and the role of their subordinates to achieve group goals (Stodgill, 1963). This two-factor (people and tasks) 
description is also referenced in other studies - consideration is the people-orientation and initiating structure is the task orientation (Michigan Studies, n.d.). This popular portrayal of leadership behavior "can be found in nearly all current theories of organizational leadership" (Short \& Greer, 2002, p.26).

\section{Contingency}

The contingency leadership theory was very active in the 1970s and 1980s (Day \& Antonakis, 2012). Contingency leadership theory gained momentum with Fiedler's (1967) work, which emphasized that leadership type and its effectiveness is dependent upon three factors: task structure, leader-member relations, and the position power of the leader (Fiedler, 1967). Task structure is the degree to which the followers' job tasks are structured and performance measured; leader-member relations refers to the trust and respect the followers have for the leader; and the leader's position power is the level of control over the followers' rewards. More simply, there is no one definitive leadership style. A style of leadership that is effective in one situation may not be effective in another. In Fiedler's view, the leader's style is a stable characteristic of the individual. Leaders who are either relationship-oriented or task-oriented can be effective if their orientation is consistent with the situation.

\section{Contextual}

Contextual approaches to leadership (e.g. authentic leadership and leadership development) have been included in a classification of leadership knows as "New Directions"; this classification appeared more often than any other in published articles in the Leadership Quarterly journal from 2000 to 2009 (Gardner, Lowe, Moss, Mahoney, \& Gogliser, 2010). The contextual school of thought remained highly active from the 1990s 
through 2010s (Day \& Antonakis, 2012; Hannah, Uhl-Bien, Avolio, \& Cavaretta, 2009). Contextual leadership prioritized the influence of the environment with the contextual factors either heightening or impeding certain leadership behaviors (Liden \& Antonakis, 2009). Essentially, leadership and context were interwoven.

\section{Transformational and Transactional}

Transformational leadership first arose in the 1970s giving emphasis to the role of the followers in the leadership process. According to Burns (1978), transformational leadership created a notable change in the lives of both followers and the organization because it reshapes values, and alters expectations and aspirations of the employees. This moral adrenaline inspires an intrinsic motivation that values relationship building and connection. In his seminal work on leadership, Burns wrote, "Transformational leadership occurs when one or more persons engage with others in such a way that leaders and followers raise one another to higher levels of motivation and morality" ( $\mathrm{p}$. 20). This type of leader is sometimes idealized because they are viewed as working for the team as well as the organization. Transformational leadership is often contrasted with transactional leadership to help illustrate one important difference between leadership and management.

In transactional leadership, a traditional approach to management, the leader appeals to the follower's self-interest through the creation of exchange relationships. The leader clarifies expectations, evaluates progress and rewards performance or corrects behavior that fails to meet the objectives (Kellerman \& Rhode, 2007). Transactional leadership relies heavily on give and take with an underlying assumption that followers are motivated by punishment and reward - extrinsic types of motivation. Transactional 
leadership is one way to operationalize management, an essential aspect of organizational function but incomplete. One limitation of this type of leadership is that it suppresses organizational change (Burns, 1978; Kellerman \& Rhode, 2007).

Transformational leadership places focus on the relationship between the leader and their constituents, of utmost importance is the leader's capacity to assist members in developing a sense of common purpose. The expectation is that the common purpose will result in a shared vision for the organization's future and subsequent organizational change (Clark et al., 1998). Transformational leadership is considered more potent, engages the follower as a whole person and "converts followers into leaders and may convert leaders into moral agents" (Burns, 1978, p. 4). Transformational leadership challenges traditional notions of power and shifts this force to support a fusion of purpose for the follower and leader.

\section{Relational}

As the power dynamic changes in the relationship between follower and leader, new descriptors of leadership emerge in the literature, words like elevating, uplifting, and collaborative are common (Burns, 1978). Shared governance is used to describe a shift in the concept of leadership from the role of a single individual to a group responsibility. In this concept of governance members are held accountable for their respective areas, faculty for producing powerful learning environments and administration for effective resource allocation and strategic planning (Lucey, 2002). Both members and leaders share responsibility for the outcomes. This participatory process inherently encourages communication and information sharing. 
Many more concepts focused on the relational aspect of leadership in the literature are worth noting such as Bolman and Deal (1984), Kouzes and Posner (1987), and Rost (1993). Bolman and Deal (1997) noted, "Both individual satisfaction and organizational effectiveness depend heavily on the quality of interpersonal interactions" (p. 158). Kouzes and Posner (1995) explored behavioral commitments that are intended to draw on individuals' strengths such as sharing power and developing talents of all individuals. Rost (1993) opined that the essential nature of leadership is the relationship. These modern attitudes toward leadership theory demonstrate a change from a leader centric approach to a group and relationship centric focus. With this change, fresh terms such as shared power, responsibility, quality of connection, and diversity emerge (Eagly, Johannesen-Schmidt, \& Van Engen, 2003).

\section{Feminine Principles}

Sally Helgesen (1990) introduced a new term "the web of inclusion" in The Female Advantage: Women's Ways of Leadership. The web of inclusion concept represented communities of sharing with both information and contacts. The women leaders in her research used words such as, "flow, interaction, access, conduit, involvement, network, and reach" (Helgesen, 1990, p. 28). Her seminal work focused on how women contribute to the workplace and not how they are deficient or need to change. One of her goals was to write about "what business could learn from women" (Helgesen, 1990, p. xx). To do this, she featured the stories, "diary studies" of four successful women leaders. Helgesen identified values such as an attention to process and not just the bottom line, an openness to understand how actions affect others versus personal benefit, a focus on community needs, an appreciation of diversity, and 
connecting the "personal, private sphere experience when dealing in the public realm" (Helgesen, 1990, p. xx). Helgesen compared her findings to those of management scientist, Henry Mintzberg (1973) to create a frame of reference for how women manage differently than their male counterparts. She found some patterns among women leaders including (a) the stance that unscheduled tasks were not interruptions - instead women leaders spent time with people because they cared and wanted to help, (b) a preference for face-to-face contact, (c) having complex networks outside work, (d) focusing on the ecology of leadership, and (e) viewing their own identity as multifaceted. Helgesen called these "the feminine principles." She saw these as the strengths of women leaders who possessed the power to unite the more traditional ideals of leadership with new directions. Helgesen advanced an innovative realm, where analytic listening and longterm negotiation created more collaborative leadership and a new definition of strong leadership.

\section{The Community College Milieu}

The community college environment is changing with greater diversity of students, expectations in accountability, technology advances, and globalization (AACC, 2012c). In response to the changing environment, the American Association of Community Colleges (AACC) with sponsorship from the W.K. Kellogg Foundation, created a national initiative known as Leading Forward (AACC, 2005). To address the leadership challenges that face community colleges, the initiative identified six competencies: (a) organizational strategy, (b) resource management, (c) communication, (d) collaboration, (e) community college advocacy, and (f) professionalism. The intention of these competencies is to guide higher education professional development 
systems and curricular content within leadership institutes of all kinds, as well as provide leaders with tools to assess their own skills. The AACC's competencies revealed core values such as equity, and outline a viable future direction for leadership in the community college. Three competencies, i.e., resource management, collaboration, and community college advocacy, related directly to women's leadership.

In the resource management competency, the AACC (2005) advanced the concept of equity and stated, "An effective community college leader equitably sustains people, processes, and information as well as physical and financial assets to ethically fulfill the mission, vision, and goals of the community college" ( p. 8). One interpretation of equitable sustainability of people is to uphold, support, and maintain the fair and just treatment of people. If equity in leadership by the community college leader is an expectation, it makes sense that equity for, and in support of, the community college leader should also be part of the equation. Access is an important aspect of equitable sustainability, more specifically, as it applies to women leaders, access to employment and opportunities for advancement to positions of leadership within the community college.

Substantial problems facing community colleges include the shortage of leaders and too few women in executive leadership positions. Problems exist when there is a difference between a stated goal and the status quo (Stone, 1997). The AACC (2005) and the Washington state community college system (Washington State Board for Community and Technical Colleges (2015a) — as evidenced by recruitment policies_acknowledged the shortage of women in executive leadership positions. However, the single most important step toward the promotion and support of women and leadership in 
the community college must go beyond increasing their representation and extend to a cultural change within the colleges' organizational culture (Tedrow \& Rhoads, 1998; Townsend \& Twombly, 1998).

The AACC's (2005) collaboration competency attempts to guide efforts in response to this problem. This competency stated, "An effective community college leader develops and maintains responsive, cooperative, mutually beneficial, and ethical internal and external relationships that nurture diversity, promote the success of all students and sustain the community college mission" (AACC, 2005, p.15). The collaboration competency resonates with a prescription for organizational change. The focus on relationships and respect for differences combined with sustainable development of people, processes, and information, this competency sets a tone for inclusion of marginalized groups.

Last, the community college advocacy leadership competency is illustrated by behaviors that "value, and promote diversity, inclusion, equity, and academic excellence" (AACC, 2012d, para. 5). This competency highlights equity along with open access, teaching, learning, and innovation, prescribing leaders to seek understand and recognition of how these issues change over time and the importance for discussion with all stakeholders.

The AACC's (2012d) leadership competencies were developed as a framework for current and future leaders to guide their leadership development. These expectations were also intended to influence curricula for program directors, human resource professionals in staff recruitment, rewards, and professional development. 
An additional and modern influence shaping leadership in community colleges beginning in the 1990s is the Learning Initiative, sponsored by the League for Innovation in the Community College. This project's purpose was to assist colleges in becoming more learning centered. The movement was initiated through a large grant that focused on 12 colleges. Their goal was to affect organizational culture, staff recruitment and development, technology, learning outcomes and underprepared students with a learning centered emphasis (League for Innovation in the Community College, 1995). The premise of the learning centered college is a deep and measurable commitment to learning throughout all aspects of the college from instruction and student affairs to administration. The outcome of success is the "quality of the aggregate learning growth possessed by its graduates" (Flynn, 2006, para. 12). To support this level of progressive learning by the students, the faculty and institutional structure must be redesigned to facilitate and sustain such a transformation. Critical components in this process are the relationships among students, faculty, and administration. They are required to maximize the contributions of each group and key to the maintenance of such a dynamic process. The learning centered college concept remains vibrant with regular conferences and meeting topics centered on practice improvement.

\section{Organizational Culture and Leadership}

Organizational culture is defined by behaviors, norms, values, and rules (Schein, 1990). Emerging debate exists around the use of an organizational culture lens as a framework to study women's leadership. For example, Schein (1980) asserted Maslow's hierarchy of needs is based on an organization of work according to men with the final stage being self-actualization in the context of economics. In contrast, Gilligan (1993) 
and Helgesen (1990) emphasized the central theme of relationships and connection for women in their development and in leadership respectively. Noddings (1984) also made a compelling argument for an ethic of caring and the role of caring in an educational context. One missing component for women in the analysis of organizational culture from a feminist perspective is the value of interconnectedness and community. Understanding the dynamics of women's relationships within the organizational culture of a college is a vital key to unlocking their success as leaders.

Organizational culture can influence curriculum and administration in higher education as resources are usually distributed based on the overarching values of the institution. When a single, predominant group creates the organizational norms and systems, which over time become tradition, biases may emerge. Leadership positions in the community college ranks have been dominated by men (Chliwniak, 1997). Leadership terminology and theory are based on male norms (Miner, 1993), and have created a standard for behavior (Chliwniak, 1997). As a result, scholars consider these organizations male-centered. The legitimacy of male-based leadership within an organization's culture is a barrier for women aspiring to be leaders as well as those in active service.

Legitimacy is imperative to the success of individuals and institutions since without it, influence over others is based primarily on the possession and formal use of power and resources. Legitimation is the process by which a system, person, or process is placed in a framework which is regarded as right and proper (Tyler \& Blader, 2005). The role of legitimacy has considerable implications for women in leadership, from two perspectives - from an emic perspective or how women feel, they are treated and viewed 
as individuals and as leaders within the institution, and through an etic outlook or how women view or assess the organization from the outside.

When employees believe an organization is legitimate, they are more agreeable to follow authorities and rules of an organization (Tyler \& Blader, 2005). This influence can be powerfully positive or negative. If males dominate leadership positions and are viewed as legitimate at the expense of women in these positions, then a bias against women leaders can be substantiated and consequently institutionalized. In this circumstance, it may be considered acceptable in behavior and belief to limit the advancement of women leaders. Conversely, if those in power endorsed women leaders, then women's leadership stands to be included as an organizational norm. Institutions lose legitimacy when they fail to follow procedural fairness norms (Hibbing \& TheissMorse, 2002; Kershaw \& Alexander, 2003). For prospective women leaders evaluating an institution or considering whether to pursue a leadership post, how well institutions comply with procedural fairness norms may influence their decision.

Tedrow and Rhoades (1999) studied how women leaders negotiate the organizational context of the community college. Qualitative data was collected via interviews of 30 senior female administrators. They found that women displayed three general strategies: adaptation, reconciliation, and resistance. Adaptation was defined as the adoption and assimilation of traditional, instrumental behaviors such as valuing hierarchy, efficiency and productivity, and less personalized communication.

In their study, Tedrow and Rhoads (1999) noted that women also downplayed gender issues. Reconciliatory leaders used both instrumental and relational behaviors as a form of defense in an effort to adapt to their environment. They acknowledged that 
women leaders did not sacrifice their status even when or if it conflicted with their beliefs, and often used double language to keep the peace. Resistance leaders made efforts to create an environment that supported relational leadership styles and valued instrumental and relational strategies as complementary. Tedrow and Rhoads identified themselves as social change agents. Many of these women used all three of strategies at different times. The results indicated that women leaders use a great deal of energy navigating organizational barriers that are rooted in gender differences.

As many scholars have noted, the organizational culture in community colleges remains dominated by males. While work has been done to develop and support women leaders among the community college ranks, Townsend and Twombly (2007) argued that National Institute for Leadership Development (NILD) and the American Association of Women in Community Colleges (AAWCC) most likely heavily influenced these national efforts rather than initiatives led by male presidential leadership. They asserted:

Thus, it appears that community college leaders, on the whole, have not been particularly proactive in efforts to make the institution an equitable educational and workplace site for women. Rather, any equity that exists in terms of enrollment of women students, the hiring of women faculty and presidents, and creation of a positive climate for them could be construed as "accidental equity" or equity by default. (Townsend \& Twombly, 2007, p. 215)

Change in the climate of these institutions is possible but as Schein (2000) argued, it is so only to the extent that the new climate proposed is compatible with the underlying assumptions of the primary culture. Along this vein, examination of institutions' assumptions and awareness of tolerances is important to understanding potential for change (Townsend, 2009). For example, what types of assumptions are made about women and minorities in these institutions? Townsend asked if women leaders are 
perceived as less effective because they lack time due to family obligations. If a woman leader makes a bad decision is it because she is a woman. Or, are assumptions made that minority leaders will lead other minorities better than or at the expense of whites?

Organizational climate will not advance until discourse is inclusive of tacit or inferred assumptions about women and minorities in the community college culture.

Additionally, discussions that include topics of difference must be careful not to equate difference with deficiency (Townsend, 2009).

\section{The Role of Gender in Leadership}

One salient aspect in the literature on leadership is the connection between stereotypical gender qualities and leadership style. Expectations about male and female leadership styles are framed by social role leadership theory (Eagly \& Johanson-Schmidt, 2001). Social role theorists asserted that leaders' roles are both defined by and confined to their position within a hierarchy and to their gender role. Traditional character traits associated with males are independence, assertiveness, logic, power oriented and risk taking (Williams \& Best, 1990). In contrast, female traits are nurturing, kindness, emotionality, interpersonally sensitivity, and relational (Schein, 1973).

Leadership behaviors and gender role expectations add an additional dimension, for example, how much latitude leaders are given by their constituents to operate within and outside of gender role stereotypes. Generally, people are more comfortable when women display communal attributes such as kindness, compassion, and collective concern. Behaviorally in a work setting these tendencies might include speaking tentatively, accepting direction, and attending to interpersonal issues. In the workplace agentic behaviors for men include speaking assertively, making problem focused 
proposals, competing for attention, and assigning tasks (Eagly, 2001). Because the majority of leadership positions have been and continue to be held by men, some researchers believe that behavioral expectations for leaders are the same or closely tied to behavioral expectations for men (Schein, 2001). Though gender-leadership expectations are becoming less frequent, they remain a factor (Sczesny, Bosak, Neff, \& Schyns, 2004).

Some research on gender leadership styles proposed that women tend to use more participatory or democratic styles while men rely more on the directive or autocratic styles (Chliwniak, 1997; Jablonski, 1996). In his meta-analysis of 162 studies, Eagly (1991) found that women were more likely than men to lead collaboratively and use shared decision-making. Women leaders tended to share information, to be caring, involved, and helpful (Helgesen, 1990). They did not view interactions with others as interruptions as opposed to their male counterparts. Overall, women leaders in these studies valued relationships, these differences are consistent with Gilligan's (1993) identification of the caring voice, which emphasizes relationships, in her theory of women's cognitive development.

Women leaders focus more on "transforming people's self-interest into organizational goals, with the women being quick to encourage participation, share power and information, enhance other people's self-worth, and get others excited about their work" (DiCroce, 1995, p. 254). This style of leadership can be described as a web, which is in sharp contrast to the traditional hierarchical pyramid. Women leaders seem to enjoy working in the center of activities rather than from the top. DiCroce (1995) included six central characteristics identified in the research on women in leadership: empower, restructure, teaching, role model, openness, and questioner. In this same vein, 
the concept of connective leadership (Lipman-Blumen, 1996) is complex and draws on a broader spectrum of behaviors that use both the self and others to accomplish goals. This style of leadership relies less on authoritarian power to govern and focuses on the value and contributions of all its members; it is also described as inclusive leadership (Helgesen, 1990). The essence of connective leadership continues with a more fluid interpretation of how leadership may take many forms throughout an organization (Bergmann, Hurson, \& Russ-Eft, 1999) and leadership that emphasizes the people in organizations, building and maintaining relationships, inclusion, and collaborative interaction (Caffarella, 1992; Helgesen, 1990; Rosener, 1990).

A review of literature research revealed sound evidence supporting the collaborative and transformational preferences in women's leadership. However, Lipman-Blumen (1996) identified a shift in this trend from an earlier study she conducted in 1984. Her later research indicated that women middle and upper managers focused more on excellent performance and task mastery when compared to their male counterparts. Lipman-Blumen's study included 2,041 women and 3,126 men and used comparative data from her earlier study. One consistency that remained across two cohorts was the levels of competitiveness between men and women. Lipman-Blumen found that women are less driven by competition than men are. Men, despite their higher levels of competitiveness, did not rank the competitive style in their top three style preferences.

How women leaders balance personal and professional life is an essential question to understanding their experience and development as leaders. In their qualitative study of 23 women, Clark, Caffarella, and Ingram (1999) used in-depth 
interviews to investigate the career path, the intersection of the professional and personal life, and the impact of gender on women in mid-level management positions. They sampled women in the fields of higher education administration, corporate organizations, and religious ministry. The women ranged in age from 30-45 years, 15 were married, three were African-American, two were Hispanic, and the others were white. Caffarella, Clark, and Ingram (1999) suggested that most women have non-linear paths of career advancement and that many do not separate their private and personal aspects of their lives from their professional work.

The career path aspect of Caffarella, Clark and Ingram's (1999) study revealed that almost twice as many women did not follow a linear career path. When asked what barriers they encountered in their ascent to a leadership position, the single greatest barrier reported was the systematic devaluation of women in our society. Several women disclosed personal examples of gender discrimination. Other barriers included the sexrole socialization and/or cultural stereotypes of women. In addition, maintaining the role of primary care-taker in their family was also an obstacle.

The intersection of professional and personal aspect of Caffarella et al.'s (1999) study suggested that while many women reported being satisfied with their career, they also admitted to paying a significant personal price for their leadership role. Balancing their family/personal life with the demands of a leadership position created mental and physical health sacrifices. Only three women in this study expressed desire for further advancement. With so few women wanting to advance, these authors determined that the personal costs of such a move are too high. 
The most startling result of Caffarella et al.'s (1999) study was that although the women in this study had cited multiple examples of personal discrimination, they did not generally identify this issue as contributing to their lack of upward mobility in their careers. As well, many of these women did not identify themselves as feminists. Caffarella et al. concluded that these women associated a negative implication to the concept of feminism and that being a self-identified feminist might detract from their status as professionals. Issues regarding gender were more regularly expressed in terms of equity concerning pay and opportunity. One woman identified herself as more of a humanist than a feminist. Caffarella et al.'s findings are significant because they indicated that while some women are successfully occupying mid-level leadership positions, many may not be acknowledging the underlying power relationships that support discrimination, resulting it its perpetuation.

Issues surrounding gender role expectations are especially relevant as new styles and standards of leadership emerge, and ideas surrounding definitions of good leadership are formed. Ayman (2004) argued that good leadership is situational and depends on the context. In this view, the appropriateness of a certain style of leadership is dependent upon the context such as the nature of the activity (e.g., emergent, long term, level of detail, social values, political landscape and climate, and organizational culture). The idea of moving among different styles of leadership as situations demand adds a dimension to the definition of good leadership. Influences and other forces within the organizational milieu further complicate how women lead. It is this intersection of women's tendencies in leadership and the realities of the organizational culture in which they lead, that warrants closer examination. 


\section{Women's Development}

The role of relationships in leadership is a salient feature in the literature and is repeated as a strong theme in other areas of women's lives including development and learning. Relationships play a key role in women's development.

Gilligan's (1993) classic study focused on women's development specifically on moral development. Until her landmark work, theories on moral development were grounded in research of male leaders. For instance, Lawrence Kohlberg's (1969) work differentiated six hierarchical stages of moral development and a battery of tests to measure moral maturity. He posited that boy's gender identity is tied to the idea of separation and individuation, with separation from the mother necessary for the development of masculinity. Another characteristic in boys' development is competitive achievement, demonstrated by competitive sports, which results in a win/lose scenario. Much of Kohlberg's findings were adopted into practice by the "moral education" movement (Gilligan, 1993). Gilligan's research was significant because it broadened theoretical boundaries and introduced the moral development of girls and women.

Gilligan (1993) reframed qualities previously regarded as women's weaknesses and showed them as strengths. Gilligan explained that in feminine development, the moral problem lies in complicating responsibilities versus a competition of rights. She asserted that the mode of resolution is contextual and narrative not formal and abstract. Males tended to mediate relationships impersonally through law and logic while women rely on close, connected communication. Another clear distinction was her emphasis on connection. Gilligan found that for girls and women the relationship is primary. The strong presence of connection between people was what inspired and created a mutual 
responsibility for one another. Gilligan concluded that presence of relationships and competing role responsibilities promoted growth and development.

According to Caffarella and Olson (1993), relationships and connectedness are critical to women's development throughout their lifespan. The purposes of their study were to (a) find alternative voices of women's development, (b) review women's psychosocial development, (c) assess new models of women's development, and (d) critique the quality of research in these areas. Caffarella and Olson reviewed 20 studies with sample sizes ranging from five to 502 and ages 15-75. From their analyses, they identified three major themes:

1. Interpersonal relationships and connection are central to women's selfconcept.

2. Women recognize the importance of taking a role but struggle with balancing intimacy and identity as with the demands of each e.g., wife, mother, paid employee.

3. Women's development is more likely to be nonlinear and diverse.

Diversity between cohorts of women is noteworthy due to developmental expectations (i.e., younger women who desire types of role models that did not exist for older women when they were younger). Both Caffarella and Olson's (1993) as well as Gilligan's (1993) research indicated that women use autonomy or separateness as a means for attaining closeness and not as some final destination in their developmentsuggesting that women who are able to care for themselves are better able to care for those around them. Women learn to balance these demands, care for others and self, through the process of developing and maintaining relationships. The interactions are a dance of needs that strive toward mutual development which align with social learning and constructivist orientations. 


\section{Women's Learning}

Learning is "a process that is used by adults for their self-development" (Knowles, 1980, p. 25). A learning theory or perspective provides “...a vocabulary and a conceptual framework for interpreting the examples of the learning we observe" (Knowles, 1980, p. 250). There is a prevailing lack of information in the literature dedicated to women's learning. The subject is frequently not considered even in the disciplines where it is most anticipated such as women's studies, education, and adult and continuing education (Hayes \& Flannery, 2000). In their text, Women as Learners: The Significance of Gender in Adult Learning, Hayes and Flannery (2000) partnered with three other authors to create a comprehensive examination of women's learning and respond to the gap in the literature. Their collaborative body of work included 269 pages with 250 references; all of the authors identified with post-structural feminist theory. The value of using a feminist lens was that feminist theory challenged the marginalization and invisibility of women. The purposes of the text were to (a) assemble knowledge about women's learning in one place, (b) frame women's learning in the environment in which they live (political, social, economic and cultural), (c) stimulate an understanding of women's diversity, and (d) recommend future direction for research and practice based on an in-depth examination of the literature. Hayes and Flannery considered salient themes found in the literature on women's learning, while others discussed feminist pedagogies, implications for educational practice, and future research and scholarship on women's learning. Their text served as a primary source of knowledge on women's learning for this review of the literature. 
A discussion of feminist theories in detail is not within the scope of this review but Hayes and Flannery (2000) presented the primary feminist theories that have influenced them as women, researchers, and authors. Multiple feminisms are the reality as feminism has many different meanings to all people. Psychological feminists are scholars who use constructs like gender role socialization to draw on this feminist perspective with an understanding of the differences across genders. Women's Ways of Knowing (Belenky, Clinchy, Goldberger, \& Tarule, 1986) is cited as an example of work from a psychological feminist perspective. Scholarship from this perspective shows the importance of challenging the "invisibility and marginalization of women's experience in the knowledge-building process" (Hayes \& Flannery, 2000, p. 11). Structural feminist theories focus on the social structures that play into the oppression of women. Relationship dynamics in the classroom, workplace, and family are examples of these social structures. Poststructural feminist theories look at how individuals are at times oppressed, at other times empowered and how experiences change according to different contexts. Language is a key area of study for poststructural feminists. It is from these three perspectives of feminist theory that Hayes and Flannery (2000) conducted their comprehensive review of women's learning.

The process of exploring women's learning is diverse. "A kaleidoscope on women's learning," describes the many feminist perspectives used to explore women's learning critically (Hayes \& Flannery, 2000, p. 1). Women's learning takes place in a wide variety of social contexts for example, in the home, the workplace, community, religious settings, recreational activities, as well as places of formal education. In all of these areas, race, class, gender, socio-economic status and other considerations contribute 
to the complexity with which women's learning is examined. In formal education, curricula including textbooks, lecture format, content and instructional materials and institutional culture must be considered. In addition, teacher-student relationship, gender dynamics in the classroom and the impact of power relationships all affect women's learning. In the workplace, preparation, guidance counseling, access, and group culture can create optimal or detrimental conditions for women's learning. As a result, how women learn can be influenced by how they feel about themselves, their self-confidence, internal strength, and self-efficacy in addition to other external factors (Hayes \& Flannery, 2000).

Understanding ways in which women view the world provides a framework for how women consider themselves and the contexts of their lives. Belenky et al. (1986) presented five different epistemological positions in Women's Ways of Knowing including: silence, received knowing, subjective knowing, procedural knowing, and constructed knowing. In the position of silence, women find themselves as mindless and without voice; they are powerless in relationships with authorities. Received knowers are able to conceive themselves capable of receiving and reproducing knowledge presented by those in authority. Subjective knowers are women who view knowledge and truth "as being privately constructed and subjectively known” (Tarule, 1988, p. 22). In this position, the knower assumes that the same is true for everyone, which leads to a perspective that must include some degree of isolation from community. Women who are procedural knowers value the learning and application of appropriate procedures in terms of both the acquisition of information and how it is communicated. Authorities are seen as the people qualified to obtain and communicate information, and are valued for 
their role. The final position is that of constructed knower. These knowers are women who see all knowledge as "contextual and experience themselves and others as capable of creating knowledge" (Tarule, 1988, p. 22). Because those in authority possess a certain amount of power, collegial relationships for the constructed knower can prosper

Two learning perspectives strongly relate to women's learning, the social learning perspective, and the constructivist perspective. The social learning perspective focuses on the social setting and assumes that learning takes place "through the observation of people in one's immediate environment... learning is a function of the interaction of the person, the environment and the behavior" (Merriam \& Caffarella, 1999, p. 265). This perspective is also echoed in Kouzes and Posner's (2007) transformational leadership theory in that leadership can be learned and is learned through observation and experience. In the social learning perspective, the emphasis is on relationship-based interactions. Consequently, mentoring and modeling are viewed as entirely natural features. Women's use of mentoring and modeling is identified as a major theme in women's learning and developmental process (Caffarella \& Olson, 1993).

In the constructivist perspective, two facets are striking- the construction of meaning from experience and the internal construction of reality by the individual (Merriam \& Caffarella, 1999). One manifestation of the constructivist orientation in adult learning is transformative learning. Women's descriptions of transformative experiences frequently include a realization of the limitations on their lives structured into cultures and institutions. The increasing awareness allows them to become the author of their own lives and to act as change agents in society. One catalyst for women's development is the feeling of confronting authority (Elias, 1991). Observation, 
interaction, understanding and confrontation appear to be key components of how women learn. Validation of one's own knowledge and acknowledgement of different ways of knowing as constructed knowing is described as:

...the position at which truth is understood to be contextual; knowledge is recognized as tentative, not absolute' and it is understood that the knower is part of (constructs) the known. In our sample of women, constructed knowers valued multiple approaches to knowing (subjective and objective, connected and separate) and insisted on bringing the self and personal commitment into the center of the knowing process. (Goldberger, Tarule, Clinchy \& Belenky, 1996, p. 5)

Hayes and Flannery (2000) highlighted identity and self-esteem in women's learning. Self-esteem relates to how one feels about their identity. Core self-esteem is associated with convictions of being loved. Specific self-esteem is situational and has to do with one's awareness of what they are able to do well in light of the expectation of others in a particular context. Insight into identity formation and autonomy is key as notions of separation, connection, and cooperation are concepts apply differently to men and women (Hayes \& Flannery, 2000). How women perceive their role, combined with relationship dynamics, and socially constructed identities are areas given significant consideration by Hayes and Flannery.

The role of voice has also been raised as an important theme. Giving voice is "the process of naming experiences that were previously unarticulated" (Hayes \& Flannery, 2000, p. 92). Naming experiences in important in establishing identity, lack of voice is limiting, insufficient words to meanings of words like women of color, co-dependency, cancer victim may require challenging existing labels. Developing voice is the "gradual unfolding with voice taking on different forms as it develops... an attempt to illuminate 
how women learn to express their identities as they change and develop" (Hayes \& Flannery, 2000, p. 93.)

Connection plays a significant role in women’s learning (Hayes \& Flannery, 2000). Connection to self and others, connection with self, subjective knowing, intuition, connected knowing, and knowing through relationships are key topics. Though the importance of connection is evidenced consistently in the literature on women's learning, Hayes and Flannery (2000) cautioned readers against over-generalizing the importance of connection since it appears to be a frequently, but singly cited truth about women and learning.

Feminist pedagogies focus primarily on the educational needs of women. They encourage social transformation by including knowers in participatory roles in social change and public policy (Hayes \& Flannery, 2000). This kind of teaching supports a more inclusive approach, taking into consideration connection and relationship along with cognitive and rational modes of learning. Five major interrelated themes are (a) how knowledge is constructed, (b) voice, (c) authority, (d) identity as shifting, and (e) positionality or dealing with differences based on the social structures of race, class, and sexuality (Hayes \& Flannery, 2000; Maher \& Tetreault, 1994).

Understanding how women learn is valuable in establishing practices that support their professional development process as leaders. Hayes and Flannery (2000) offered several suggestions for future research and practice. Among their action items are (a) designing learning for the whole person, recognizing women as feeling and thinking people, (b) respond to women learners from different social contexts, (c) increase awareness around assumptions about women as learners, (d) actively question how 
administrative and instructional processes impact women learners, and (e) investigate the role of privilege and power and the educational status quo to create a more complex and accurate picture of women as learners. Hayes and Flannery recommended basic and reasonable examples of future research that will likely contribute to the foundational knowledge on women's learning forming a more complete picture of how women learn leadership.

\section{Summary of Literature Review}

In this review of the literature, I presented a theoretical framework based on the transformational leadership model proposed by Kouzes and Posner (2000). I provided a brief historical review of the literature on leadership including the great men, trait, and behavioral leadership theories. To clarify the difference between management and leadership, I contrasted transformational and transactional leadership. I also discussed relational leadership as it emphasizes shared power, diversity and the quality of connection. Beyond leadership styles and behaviors, I reviewed the context in which leaders practice leadership, which necessitates the inclusion of organizational culture, legitimacy theory, and gender role expectations. Finally, I offered a focus on women's development and learning to create a backdrop for this research study on how women learn leadership. 


\section{CHAPTER 3: METHODS}

The purpose of my study was to examine some of the factors that contribute to women executive leaders' success specifically: (a) how women experience their leadership role in the community college, (b) how women vice presidents use transformational leadership, and (c) how women administrative vice presidents have learned to lead. I believe this inquiry is important for many reasons including illuminating the underlying issues related to the underrepresentation of women in leadership. Community colleges face a growing shortage of leaders. The vice president post is an important feeder to the presidency and as the leadership crisis looms large, community colleges must consider a broader representation of leadership experiences to meet the demand (AACC, 2002). More than half of college students are women, yet, less than one third of community college presidents are women (Kampel, 2010), and only $13 \%$ of those represent marginalized groups (Amey \& VanDerLinden, 2002). This poor reflection of the community in the leadership ranks is hypocritical given that community colleges exist to serve the community. Current research asserts that community college leadership remains grounded in male dominance (Outcalt, 2002; Townsend \& Twombly, 1998). Further clouding the issue, research on women in community college leadership is limited. More studies have focused on the experiences of female faculty than women leaders (Townsend \& Twombly, 2007). My intention is for the results of this study to add to this limited body of research. Additionally, results of this study could inform leaders, policy makers, and others concerned about women's advancement in leadership positions. 


\section{Research Questions}

For my study about women leaders in community colleges, I focused on three questions:

1. How do women experience leadership in administrative vice president positions in community colleges?

2. How do women in administrative vice president self-report use of transformational leadership practices?

3. How have women administrative vice presidents in the community college learned to lead?

\section{Research Perspective}

The theoretical framework for this study, transformational leadership theory, was appropriate because of its emphasis on relationships - a central theme of women's learning and development. Similar studies using Kouzes and Posner's Leadership Practices Inventory have been widely used to study women leaders (e.g., Aaker, 2003; Brightharp, 1999; Burkhart, 1999; Gorenflo, 1994, Ottinger, 1990).

To answer the three research questions in the study, I used an exploratory qualitative design. A qualitative orientation allows for a broader range of contextual variables to be included enhancing the quality of the research (Bryman, Bresnen, Beardsworth, \& Keil, 1988). The qualitative research approach equips the researcher to explore experiences, behaviors, and feelings of participants and emphasize these elements to create understanding. Interviewing is an especially relevant data collection method to studying women (Belenky et al., 1986; Hegelsen, 1990; Oakley, 1981)—one particular advantage to this approach in this study is the depth of understanding that develops - the 
participants' voice is remarkable. A closer, personal connection, and relationship can be created that give audiences an exclusive perspective, through the eyes of another, rich with detail and senses.

Case study design in the qualitative approach is an ideal fit for this study because the research literature on women community college administrative leadership is limited and a notable feature of this strategy is the relevance of individual storytelling based on participant' experience (Creswell, 2005, 2009). Merriam (2009) defined case study as "an in depth description and analysis of a bounded system" ( $p$ 43), which is consistent with the definitions of other researchers (Creswell, 2007; Stake, 2005). In this case study, the bounded system is women leaders serving in the vice president role further defined by the service unit, which is administrative, within a community college system. Access to this population is challenging due to low representation and geography, but case study design offered a framework to study this unique set of leaders in greater depth.

In this study, two characteristics of qualitative research were most relevant: (a) the perceptions of the participants was important and capturing their ideas was necessary in order to accurately measure their construction of reality, (b) meaning making was restricted to the participants with deliberate effort made to avoid being imposed by the researcher (Wiersma, 2000). A qualitative data collection method, interviewing, was appropriate because it brings an authentic voice to the participants' experience and does not limit individual expression. 


\section{Participants}

I recruited women who served as administrative vice presidents in public community colleges throughout the Western United States as participants for this research study. The Vice President of Administrative Services position is a key member of the executive team. The position is most often responsible for the college's budget and overall financial management, legislative and policy matters, contracts and partnerships, material acquisition, property and space management, and campus safety. Depending on the structure and size of the college, information technology and human resources may also be a responsibility of the Vice President of Administrative Services. These critical responsibilities afford this vice president a unique vantage point from which to observe, understand and act on opportunities and respond to challenges that affect the college as a whole.

This position is an uncommon feeder position to the presidency, $5.4 \%$ versus $37.3 \%$ who come from a chief academic officer position (AACC, 2006). Given the shortage of leaders and the increasing financial struggles community colleges experience, the Vice President of Administrative Services position could be considered more often that it is currently is, a pool from which to recruit presidential candidates. As such, it is important to understand how these executive leaders experience and learn leadership in the community college.

In the selection step, I followed a purposeful sampling process, which is "based on the assumption that the investigator wants to discover, understand, and gain insight, and therefore must select a sample from which the most can be learned" (Merriam, 2009, p. 77). In this study, the purposeful sample I chose included women administrative 
services vice presidents from public community colleges in small, medium, and larger community colleges as well as single and multi-campus districts. Based on student enrollment the colleges represented range from 2,000 to 50,000 and are located across four states, Oregon, Washington, Idaho, and Wyoming. Many colleges have a similar organizational structure in that there is a board of trustees, a president or district president, vice presidents, directors, managers, and classified staff.

I invited 21 women who hold the title of administrative vice president to participate in the study. I identified participants through computer-based searches using institutions and state board websites' public directories. I conducted a search using the identifier administrative (services) vice president. Twelve participants volunteered for the study. Following the interview, I invited participants to complete a survey that measured through self-report the frequency of their transformational leadership behaviors.

\section{Limitations}

The selection process of the participants themselves was limited by the realities of recruitment including availability (i.e., low numbers of women in leadership positions), their interest, professional schedules, and geography. A selection bias may have occurred between those who volunteered to participate in the research study and those who declined.

In this study, the data collected was based on self-report. An error or measurement bias may have occurred during the process of data collection as the participants rely on their memory to reflect on leadership style and practices and to recall past experiences. The participants, knowing the intention of the study may also have 
given a more encouraging depiction of their experience. With regard to my interpretations, an expectation bias was possible that could have be made in favor of an expected outcome.

Other limitations of this study were (a) scant literature about women administrative vice presidents in community colleges, and (b) the small number of participants in this study. Although the survey instrument used has a high level of validity and reliability (Kouzes \& Posner, 2003a), psychometric properties some restrictions are still likely. The intentional focus on the community college as a single aspect of higher education naturally limits generalization to other facets of higher education such as private and public colleges and research universities. The literature suggests women's experience with leadership is different in community colleges from other areas of higher education (Phillippe, 2000). As such, the results of this study should be interpreted with the limitations of that context in mind. The attention of this study on leaders in the Western United States is limited to the regional cultural influences of this area.

\section{Data Collection Procedures}

Prior to beginning this research study, I obtained approval from the Human Subjects Research Review Committee at Portland State University. To protect participants' confidentiality, I used pseudonyms and concealed information that could reveal the participants' institution. I sent an invitation to participants via email explaining the purpose of the study and the process. Once participants agreed to join the study, I secured a signed informed consent (see Appendix A) and sent the demographic survey (see Appendix B) via email. I used the demographic survey to gather basic 
information about the participants including their leadership experience and educational background. Participants provided written responses and returned the demographic survey via email.

I conducted the participant interviews individually and over the phone. The geographic locations represented by those who volunteered to participate were broad making face-to-face interviews for all participants logistically undesirable. Therefore, I chose not to give participants an opportunity to interview in person by design as to create consistency across all interview sessions.

All of the interviews were digitally recorded. Access to the data was limited to the researcher, her doctoral advisor, and a transcription service. Data were transported via secure server with a password-protected drive. All data in hard copy was stored in a locked file cabinet when not in use.

An analysis flowchart for each research question is presented in Table 1. I used the demographic survey for initial data gathering and to confirm that participant requirements for inclusion in my study were met (e.g. position title, department). Other questions such as, what leadership positions have you held and for how long, served as reminders for possible probes during the interview. Additionally, these questions helped the participants to understand better some of the information we would explore during the interview. The majority of the data gathered for this study came from participant interviews with additional data sources serving as support. 
Table 1.

Data Analysis of Research Results

\begin{tabular}{lll}
\hline Research Question & Source of Data & Analysis Procedures \\
\hline 1,3 & $\begin{array}{l}\text { Demographic variables } \\
\text { obtained from survey } \\
\text { questionnaire; Responses } \\
\text { from Leadership Practices } \\
\text { Inventory (LPI-SELF) }\end{array}$ & Frequencies \\
& $\begin{array}{l}\text { Responses from Leadership } \\
\text { Practices Inventory (LPI- } \\
\text { SELF) }\end{array}$ & Correlations \\
& $\begin{array}{l}\text { Responses to open-ended } \\
\text { questions }\end{array}$ & Text analysis of themes \\
\hline
\end{tabular}

Following completion of the interviews, I invited participants to participate in a transformational leadership practices inventory (i.e., Leadership Practices Inventory). Information provided via email contained instructions on how to complete the paper inventory. Using Kouzes and Posner's (2003a) Leadership Practices Inventory, I examined how women self-report use of transformational leadership practices in their community college roles. The instrument identified and measured five practices that represent personal best leadership practices. Once data collection was complete, I scored the Inventory and returned the results to the participants.

\section{Instrumentation}

The instruments used to gather data for this study were the demographic survey and the Leadership Practices Inventory -Self (LPI). The demographic survey provided 
basic background information and aided in screening. Completing the LPI was optional and offered to participants to thank them for their participation in the study.

\section{Demographic Survey}

The demographic survey included seven open-ended items: (a) current position title, (b) current college and department affiliations, (c) leadership positions, (d) number of years of leadership, (e) educational background, (f) specialized leadership training, and (g) race/ethnicity (see Appendix B). I used data from the demographic survey to screen and confirm applicants' qualifications for inclusion in the study and as a guide during the interview process.

\section{Interview Protocol}

To guide the development of the interview protocol, I wrote and piloted the interview. A woman executive level leader volunteered to participate and based on the data retrieved, I modified the number and wording of the interview questions. These changes improved the flow and concision of the interview protocol.

I used a semi-structured interview protocol to guide participant interviews. Because the format was open and flexible, the semi-structured interviews allowed participants to refine their reflections about their leadership. In general, the interview questions explored the specific pathways each leader had found to learn leadership and their perspective on their experiences as executive leaders. Additionally, the questions (see Appendix C) probed the leadership experiences of the community college vice presidents, their identity as women leaders, their leadership practices, the organizational culture, future goals, and their advice for aspiring women leaders. Data from the semistructured interview helped to answer research question one, two, and three. 


\section{Leadership Practices Inventory}

The Leadership Practices Inventory (LPI) SELF: A self-assessment and analysis (Kouzes \& Posner, 2003a) uses a set of behavioral statements (see Appendix D). Kouzes and Posner (1987) developed these behavioral statements based on their earlier leadership research. The LPI SELF inventory is a 30-item assessment tool that uses behavioral statements that allow leaders to measure the regularity of their individual leadership behaviors. The inventory uses a 10-point Likert scale to respond to questions related to their own practice (i.e., $1=$ almost never, $2=$ rarely, $3=$ seldom, $4=$ once in a while, $5=$ occasionally, $6=$ sometimes, $7=$ fairly often, $8=$ usually, $9=$ very frequently, $10=$ almost always). Each of the five leadership practices has a scale of 1-10, and scores range from 6 to 60. According to Kouzes and Posner (2003a):

The Leadership Practices Inventory (LPI) was developed through a triangulation of qualitative and quantitative research methods and studies. In-depth interviews and written case studies from personal-best leadership experiences generated the conceptual framework, which consists of The Five Practices of Exemplary Leadership®: (a) Model the Way, (b) Inspire a Shared Vision (c) Challenge the Process, (d) Enable Others to Act, (e) Encourage the Heart. (p. 1)

Reliabilities of the LPI range from .71 to .85 across the five practices. The internal reliability was above .75, as measured by the Cronbach's Alpha ( Kouzes \& Posner, 2003 c). Notably, the LPI SELF has been administered for well over a decade. The LPI is an appropriate instrument as it is representative of current and effective leadership practices (Taylor, 2002). I used the LPI data from the LPI SELF inventory to respond to research question two.

I chose the LPI specifically for its set of leadership behaviors and practices that seem to resonate with the foundations of transformational leadership and its focus on 
relationships. There is a strong emphasis on trust in the leader-follower relationship, which is a critical element of connection and a theme in women's development. The LPI is an individual inventory and designed to be taken as a self-assessment. This self-report format is a good complement to interviewing as the primary data gathering method for my study. A variety of instruments are available that measure leadership styles, some from a 360 degree perspective involving direct reports, but given the scope of this study were not an appropriate fit. Other instruments such as the Multifactor Leadership Questionnaire (MLQ), (Bass \& Avolio, 1995) is more broadly based measuring transactional and passive leadership behaviors along with transformational practices, so it was not the best choice given the focus of this study.

\section{Data Analysis}

After conducting the interviews, I used a transcription service to transcribe the data. Then, I reviewed the transcriptions systematically for accuracy. Subsequently, I verified responses with the participant through member checking to confirm their understanding. This step included sending the interview transcript along with the featured quotes to the participant via email, giving them the opportunity to read their words, and make any changes to them.

Data analysis followed Berg's (2001) steps for data reduction, display, and conclusions and verification. Qualitative data gathering usually produces a voluminous amount of raw data. Data gathered from interviewing twelve women vice presidents necessitated data reduction steps in order to be useful. Data reduction describes the process of distilling this data from in-depth interviews to transcription, contextual analysis, written summaries, and coding to analytic themes. Data reduction is a 
transformational process that is carried out throughout the life of the research. For example, to reduce the data during the interview process, I began with questions that were more general and probed using more specific information as the interview continued.

I read and reviewed the transcripts for similar words or ideas used by the participants to describe a feeling, event, or insight related to their experience in the community college, transformational leadership, or learning leadership. To implement quality control measures, I considered accuracy through a series of readings and rereadings in the coding step. I routinely used note taking to identify information that required additional clarification during the coding process (Fowler, 2009). My initial code list included 84 entries. As I reviewed the transcripts, I assigned a color code to identify possible themes as they related to research question, one, two, or three.

Data display refers to the presentation of the data in an organized and compressed way that permits analytical conclusions to be drawn; examples may include clusters of information. I grouped the data by research question and noted the quotes (participant, and page number). This step yielded eight clusters for research question one, five for research question two, and five for research question three. I considered themes significant if half or more of the participants identified them. Some examples of the themes identified included service, quality of leadership connection, inspiring a shared vision, and accepting additional duties.

During the qualitative analysis, I identified themes related to women's leadership experiences. I drew conclusions based on the patterns identified in the data and verified that these were not a result of bias. One method for drawing conclusions was to examine 
carefully the analytic steps taken to arrive at the conclusion, I did this by reviewing the quotes I had identified in context, examining them individually and as a set or cluster and in response to the research questions. I repeated these steps multiple times.

As an additional step in the verification process, I sent a copy of the transcript and list of quotes to the participant following the interview to check for accuracy, a procedure commonly known as member checking. Participants had an opportunity to review the transcript and identified quotes to make clarifications or changes. This process helps to ensure the accuracy of the data. Verification also included an in-depth review to ensure that all procedures were documented clearly, so that future researchers could replicate the study and produce similar conclusions.

\section{Role of the Researcher}

My assumptions relate directly to my perspective and experience as a woman and former administrator in a public community college. Without question, I have personally experienced and witnessed challenges facing women leaders. However, during this study, I also learned about opportunities in the community college that I did not experience while working at a tier one institution. As the community college in general attracts a wide variety of people, I did anticipate that I might hear a variety of leadership experiences from the participants of this study. I was curious to know in what ways women leaders learned leadership and any opportunities they may have found or created that influenced their success and development as leaders.

In an effort to suspend my personal bias regarding challenges, I intentionally asked open-ended and neutral questions. For example, "what experiences have best supported you in learning to lead?" and, "describe how the organizational culture has 
impacted your experience as a leader?" To limit priming the participants I also limited details about my professional life and experiences in the community college until the end of the interview and only when the participants asked questions directly to me. My goal in doing this was to minimize any tendency for the participants to skip over details or make assumptions about my understanding of the community college culture or commonalities we might share as women in community college administration. As an additional strategy to minimize researcher bias I provided copies of the completed interview transcripts to the participants along with the quotes I had selected for inclusion in the dissertation. By allowing them to see the quotes themselves and within context, my goal was to allow them an opportunity to correct any miscommunications and maximize clarity of meaning. 


\section{Chapter 4: Results}

In this chapter, I present the results of the study. First, I review the purpose, research questions, participants, analysis, and limitations. Considering the influence leaders have on institutional success, the shortage of leaders and the increasing role of women executive leaders in the community college, the purpose of this study was to explore some of the factors that contribute to women executive leaders' success. This purpose was formulated into three research questions: (1) how do women experience leadership in administrative vice president positions in community colleges?, (2) how women vice presidents self-report the use of transformational leadership practices, and (3) how have women administrative vice presidents learned to lead. I address each question in detail with analysis of the data.

\section{Participants}

I identified prospective participants through database and Internet searches. Specifically, I recruited women leaders in community colleges with the title of Vice President of Administrative Services or equivalent to participate in the study via email. I invited 21 women leaders to participate and 12 accepted. To recruit this final complement required follow-up contact by phone and email. I assigned pseudonyms to respect the participants' privacy.

The following is a brief summary of the demographic information gathered from the survey. The 12 participants held position titles of Vice President and further identified by their business unit (e.g., Administrative Services and/or Finance). To maintain confidentiality, the participant specific position and department titles were 
intentionally not included in this report. The leadership experience ranged from 8 to 30 years with an average of 19.3. Four of $12(25 \%)$ participants reported having attained a bachelor's degree with the remaining $8(75 \%)$ having earned a master's degree. The majority, 8 of $12(75 \%)$, identified as White; three chose not to identify their race.

The leaders in this study have vibrant and diverse backgrounds each with their own unique personality and path to the executive post. I offer a brief summary of these stories as an illustration of these points.

\section{Hillary}

"I'll learn something, and that's how I've come on every single thing I've done, is that, “...I will learn something from this. There are lots of tears at times. I'm not going to say I never cried about it."

Hillary gained valuable work experience over many years working in the community college system. She found herself underemployed and regularly eager to take on more responsibility; when opportunities arose, she took them. Having the experience of several accounting positions, she moved up quickly and attended classes to earn her degrees. She was good with people and naturally skilled in developing strong relationships with others. As a deeply caring person, she learned over her career to balance her easy empathy for others with what she calls her, "armor." Hillary chose to adapt her own leadership style to meet the needs of her employees. She noted that she has found it necessary to be prepared for others to act unprofessionally or anticipate that things might get personal. Hillary valued "leadership for all" and believed in transparency. She described herself as being "more about the people than the money" and being most comfortable when operating behind the scenes. 


\section{Morgan}

“After I got unsolicited feedback, I'm like, wow, that's very helpful. Give me more feedback."

Morgan was in the Future Farmers of America organization in high school and wanted to be the Club Sweetheart; instead, she was elected President. Out of high school, Morgan went to college but dropped out due to a lack of support. For 10 years, Morgan took a series of entry-level jobs, but after a short time in each, she always found herself moving up and given more responsibility. She described herself as a direct, take-charge person who enjoys hands on problem solving. Morgan appeared to be likeable and organized. Before returning to college, she took a certification class; with these new skills, she started her own business - an operation that continues to be family run today. Once she returned to college, she earned her degree in accounting. She credited in part, accepting new duties and having a series of strong female mentors for her ascent to higher levels of leadership. Morgan said that her focus on relationships and ability to recognize different talents in others by letting them play to their strengths is a very effective way to build morale, saying, “...interconnectivity, that —I will hang my hat on that. I really do."

\section{Maren}

"It breaks my heart when my colleagues talk about students getting in the way." Maren has been a passionate advocate for students of color. Brought up in a large family, Maren lost her parents at an early age and was raised by her siblings and aunt. As the youngest sibling, she had important family responsibilities (e.g., paying bills and maintaining the household). She described her family as being financially disadvantaged. 
They believed deeply in the value of education and her older siblings worked and attended college. Her family was fueled by the idea that education "was a way that we could move past our current condition" and Maren was expected to model responsibility for her young niece and nephews. She moved away to attend the university and took student leadership roles, worked part-time and actively participated in workshops and opportunities to learn. She found full-time work with the university and enthusiastically embraced her work, assisting students of color and their families. She advanced professionally and held many high-level leadership roles including a job in the chancellor's office and gained valuable system-level work experience. When Maren was working on her graduate degree, she was diagnosed with a serious illness. The treatment interrupted her progress; yet, she re-engaged in graduate work—starting over after a long break in another program. This experience and others revealed a pattern of resilience and love for learning throughout her career. Always invigorated by her passion for students of color and education, Maren directed her energy in lifting others up, teaching, and being a voice of change.

\section{Susan}

“....if I'm going to complain about something in my job, I'm not going to do it with anybody here... going to it with somebody I trust, where I can bounce things off of, where it's confidential."

Susan started her career in public accounting as a C.P.A. She worked in auditing and then private industry banking. She also participated in leadership training during this period. Susan was married and took a few years away from her profession to have children. When she returned to banking, she experienced the challenges of balancing 
professional demands with family responsibilities and believed she was penalized by her employer as a result, and was passed over for a promotion — her boss cited her schedule. With a strong interest in education, Susan found work in education and research and was appreciative of the flexibility offered with her new role. She was very attracted to the community college because of the close contact with students and taught finance and accounting. She always wanted to be a professor and had a desire to continue her professional development, so she attended graduate school in educational leadership. She believed in complete honesty and integrity in her dealings with others and expected it of others as well, including her boss. A consummate professional, Susan described herself as a servant leader, to her this means helping employees "find the tools, breaking down barriers, and helping them solve problems."

\section{Nell}

"I have found throughout my years that you can get people to look at you as a leader not by telling them you're a leader but by showing them you're a leader."

Nell had a traditional family upbringing and was encouraged to start her own family after high school. She married and had children. When she was 30 years old, she decided to pursue her degree. She was an excellent student, earned her degree in accounting and quickly recruited into public accounting. Nell wanted broad experience and envisioned herself in a leadership role. She gained essential work experience with an international accounting firm, a community college, and a large retail company; she also served as a trustee for a nearby college. Through these experiences and networking, she established important relationships and actively recruited for the Vice President of 
Administrative Services post. Nell operated with the belief that every person has value and that even in disagreement much can be learned "if you have a mind for that."

Zoe

"I was able to show that integrity through my actions..."

Zoe, a mid-career professional, exhibited vibrant enthusiasm and focused on selfdevelopment and personal reflection. She spent most of her early career with one community college and took classes to earn her accounting degree. Working on campus in her field, she was able to apply what she learned and credits supervisors and mentors who invested in her development for her rapid advancement. She knew she wanted to be an executive leader so she began an M.B.A. program. As an astute observer of campus politics, Zoe decided she would succeed best as an executive leader at a different institution and accepted a Vice President of Administrative Services position in a smaller, neighboring community. She has loved teaching and found working with students a rewarding way to connect. Zoe considered one of the most important leadership practices is honest and transparent communication with the understanding that it is foundational for building trusting relationships. She has strived to exhibit this leadership practice. Zoe believed she is in the right position at the right place and proudly reported that her personal values mirror those of her current institution.

\section{Bonnie}

"I still feel like I'm in the little boys club, and it takes some effort sometimes to not let that become part of your thought process, because there's nothing you can do about it really except be competent." 
Growing up Bonnie's father held a high-level leadership role in education and she watched him work through challenging situations. She started working part-time on campus after moving to the city to marry her husband. At the college, she had a series of jobs in business each with increasing levels of responsibility. She balanced work with school and earned her undergraduate then graduate degrees. Bonnie said that her relationships with her supervisors were "priceless" walking her through new duties, supporting her learning process. Profoundly inspired by one supervisor in particular, she described as "one of the most reasonable and intelligent people as far as problem solving that I'd ever worked with"; Bonnie admired her and tried to emulate her leadership. As a leader, she has learned to listen for understanding and let "people tell me in their own way, and through their own processes what it is they want to achieve, and then I can help." Bonnie chose to prioritize patience in her leadership practice and operate with a sense of humor.

Joan

"You're looking for other people for guidance and then we realize well hey, we're right there at the top. It's us. We have to step forward to really be those leaders that we need to be."

Joan was a non-traditional student, raised a family, and returned to college in her thirties. She graduated from a competitive accounting program, was heavily recruited into a for-profit firm, and promoted quickly to management. After moving out of state for family reasons, she accepted the vice president position. Her unique and varied career path prepared her well for the variety of challenges she faces as a vice president. She is a tenacious and authentic person who wants others to find success. Although she was told 
by a professor to avoid being too aggressive (as a woman), she believed that it is necessary to be strong and assertive and not worry about what people think of you. Looking back, even when she felt terrified inside she says, "You have to have calmness..., failure is not an option." As a leader, Joan wanted employees to identify their role and frame their work in the larger picture, she perceived herself delegating, empowering, and trusting people.

\section{Sadie}

"When you really don't want to stand up is when you have to stand up."

Sadie, a forthright person with noticeable strength, confidence, and a heart for social justice, has focused on treating others with respect, not because she has to but because that is who she is as a person. Sadie said she has a lot of empathy for everyone throughout the organization. With a tough no-nonsense air about her, Sadie has not wanted people to fear or respect her because of the position. Admitting to mistakes and playing fair were among the key behaviors she strives to demonstrate; thus, earning the respect of others. She has solid skills and experience in a technical field and as a faculty member. Moving into an accreditation project gave Sadie an opportunity to work with many employee groups across the college and gained a more global view of college operations. She described the vice president's job as a "problems are us kind of job" as it is multifaceted with many areas that affect a large number of people. She saw her leadership responsibility as a practice in bridging the silos that often divide an institution. Sadie said, "You can learn this job. The hard part is to learn that human interaction." She has tried "to come at things without preconceived notions ... asking a lot of questions to get the right data." Sadie believed, "a lot of leadership is taking people through." 


\section{Gail}

“...I want to help others improve their lives and the lives they touch...doing this fulfills my life's purpose."

Gail had a full career as an accountant until her late 30s, when she was diagnosed with a debilitating condition and took a break from her career. During this time, she did something she had always wanted to do, go to college. She said it "just totally changed me for the good." Gail had experience serving on non-profit boards, often serving as the treasurer because of her experience. She had good access to mentors both in supervisors and in her family. With her degree in hand, and able to return to work, she progressed quickly. About her job, Gail said, "I get to live my passion every day in my job, because I really wanted to be part of a community college." The "collegiality and the participatory governance modeling" is an important draw to the cause. She saw herself as a leader and believed to be successful, "you really have to have a servant's heart." Reflecting on this balance in leadership, Gail said, "I did learn a lot...part of it is that being compassionate isn't a weakness, being manipulated is." She considered community college leadership a privilege and intentionally challenged herself to improve and grow.

\section{Vicki}

"I don't care what level you are in the organization. That is not a measure of the contribution. It takes all of us to get it done."

Vicki has always needed a good cause to direct her energy. She required an intellectual challenge to feed her insatiable curiosity. Vicki began her career in management and has a graduate degree in business. A variety of professional experiences including legislative work, budget oversight, and performance auditing gave 
her ample exposure to develop. Always drawn to a challenge, she sought additional responsibility, but only in jobs that were interesting to her. In her view, commitment to the vision is essential for success. This thinking applied to her employees as well - she has been a dedicated advocate, with an authentic interest in their development and invested in them financially through professional development. Vicki avidly pursued mentors to facilitate her own development. She recalled one mentor who gave a powerful lesson on organizational culture transformation. As a result, she has experienced "great alignment in my work life" where the distance between who she is at work and at home, "is not that great."

\section{Peggy}

"No, you should have a voice in this too."

Peggy focused on her marriage and family first, her husband was in the military. While living overseas for his career, she had a position in education. After his tour and stateside, she earned her undergraduate degree and took a position as a tax auditor. Other positions followed, working in finance for health services, as a payroll manager and legislative work. She described herself as not very social and her leadership style as atypical, with a tendency toward sharing power, she is not, "your boss." Peggy loved details and numbers but genuinely valued the human side of the work. She has left the backdoor to her office open to encourage informal visits. She wanted to be available and accessible when needed most. Peggy also wanted to know what makes her employees happy and what she can do to help them achieve their goals. She has been known for her fair approach to conflict and for her ability to listen and would like her college to be known as "the best place to work in the state." 


\section{Analysis}

The Human Subjects and Research Review Committee (i.e., Institutional Review Board) at Portland State University approved my study. Subsequently, I sent informed consent letters and demographic surveys via email and 12 returned completed. Next, I conducted the interviews individually over the phone and digitally recorded each one. The average interview length was 59 minutes. I used a transcription service to transcribe the interview data. To confirm understanding, I verified participants' responses through member checking. In other words, I provided copies of the verbatim responses to the participants for their review and correction. Following the interview, I sent the participants the Leadership Practices Inventory, (Kouzes \& Posner, 2003b). Three of 12 participants chose to complete the survey.

All 12 participants received the LPI, though only three completed it. The LPI was not a required part of the study and offered to the participants as a thank you for their participation. I scored their inventories and determined the highest ranked personal leadership practice, Enable others to act, was consistent across the three participants with one variation. The top score for one participant showed a tie between Enable others to act and Model the way. The results of the LPI were consistent with the subsequent analysis of interview data. These scores may be representative of the larger pool of applicants; however, without a larger sample, this conclusion is limited.

To analyze of the interview data, I followed Berg's (2001) steps for data analysis. First, I engaged in data reduction by reading and re-reading transcribed interviews to organize the data into a more manageable arrangement with broad groupings relating to each research question: (a) experience, (b) transformational leadership, and (c) learning 
leadership. Then, within each of these broader groups, I used an iterative process to inform the development of codes. Next, to achieve the data display step, I conducted a systematic evaluation and content analysis so that I could identify and examine patterns. In the final step of analysis, I identified themes and drew analytic conclusions. I developed a research question flow chart with associated themes and sub-themes (see Figure 1). I considered themes significant if they were identified in half or more of the study participants' interview data. In the following section, I address and discuss each research question by theme and subtheme. 


\begin{tabular}{|c|c|}
\hline \multirow[t]{3}{*}{$\begin{array}{l}\text { Research Question } 1 . \\
\text { How do women experience } \\
\text { leadership in administrative vice } \\
\text { president positions in community } \\
\text { colleges? }\end{array}$} & $\begin{array}{l}\text { Theme: Gender Culture } \\
\text { Sub-themes: } \\
\begin{array}{ll}\text { a) Communication } \\
\text { b) Self-regulation } \\
\text { c) Competence }\end{array}\end{array}$ \\
\hline & $\begin{array}{l}\text { Theme: Service } \\
\begin{array}{ll}\text { Sub-themes: } & \text { a) Students } \\
& \text { b) Institution } \\
& \text { c) Power of higher } \\
& \text { education }\end{array}\end{array}$ \\
\hline & $\begin{array}{l}\text { Theme: Quality of leadership connection } \\
\text { Sub-themes: a) Honesty and integrity } \\
\text { b) Valuing the "whole" } \\
\text { person }\end{array}$ \\
\hline
\end{tabular}

Research Question 2.
How do women administrative vice
president self-report use of
transformational leadership
practices?

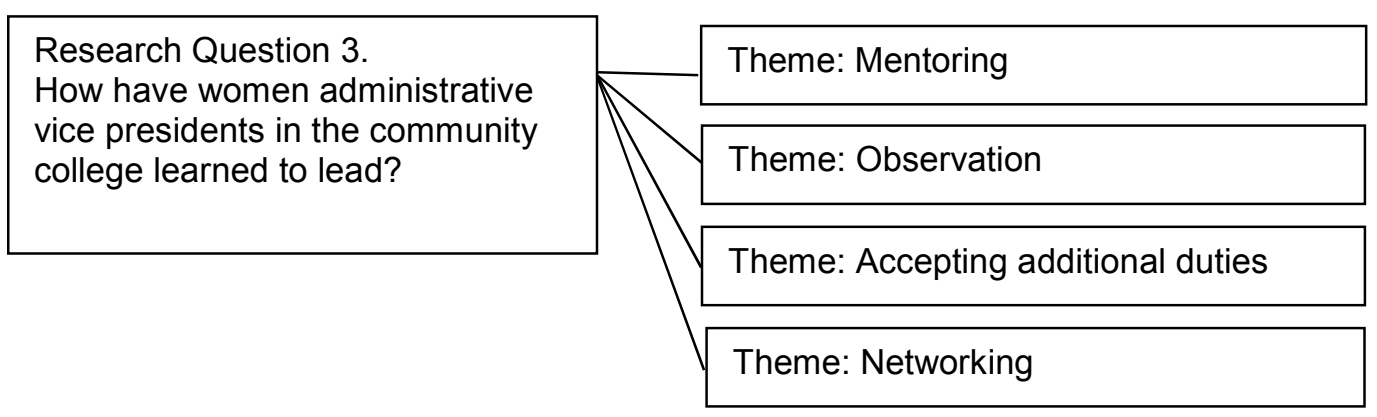

Figure 1. Research question flowchart. This figure outlines the research questions, themes and sub-themes. 


\section{Results by Research Question}

In this section, I present the results of this qualitative study by research question: (a) how do women experience leadership in administrative vice president positions in community colleges?, (b) how women vice presidents self-report the use of transformational leadership practices, and (c) how have women administrative vice presidents learned to lead. The three areas of focused inquiry are leadership experiences, transformational leadership, and learning to lead.

\section{Women Vice Presidents' Leadership Experiences}

Women leaders reported a variety of ways in which they experienced leadership in the community college. The role of gender, their commitment to service, and their connection with others were dominant features.

How do women experience leadership in administrative vice president positions in community colleges? Analysis of the participant interview data led to the identification of three themes related to how women experience leadership: (a) gender

culture, (b) service, and (c) quality of leadership connection. The theme, gender culture, represented how the role of gender has affected women's leadership experience in the community college. The women leaders in this study readily expressed a strong motivation for their commitment to their work. The second theme, service, described some of the underlying forces connecting these participants to their work. The third theme, quality of leadership connection, characterized what these women leaders valued in their leadership role and how they view their constituents. 


\section{Gender Culture}

The majority, 8 of $12(66 \%)$ of women leaders in this study described examples of how gender culture in their leadership role has impacted their experience. Their reference to gender culture includes gender roles and behavioral expectations related to gender in the communication and leadership domains. During my analysis, I identified three sub-themes to gender culture: (a) communication, (b) self-regulation, and (c) competence. Verbatim quotes extracted from participant interviews provide evidence of these sub-themes.

Communication. The communication sub-theme illustrated the ways in which women leaders in this study have perceived and sometimes found it necessary to modify their communication style based on their experience of gender in the workplace. For example, Hillary is an experienced professional who came into the vice presidency with a background in accounting. She is a self-described introvert with a palpable loyalty toward fairness in her practice of leadership. She reflected on gender culture communication in this way following a presentation, "I think because I'm in the role I am in, women try to embarrass me at times, and they tried a couple of them to embarrass me, and I thought they would do the same thing if it was a man." In another instance, Zoe, warned of the challenge women face in pursuing career advancement assertively, "It's really difficult for women to communicate they want to advance without looking like they're gonna bowl everyone over. 'Yes I want that person's job so I'm gonna undermine them till they're not here' that's the perception." Zoe, a mid-career Vice President with an optimistic attitude, focused on self-development and was quick to 
credit the influence her mentors have had on her leadership development. Similarly, Nell acknowledged a difference in how male and female leaders are perceived; she stated:

...the perspective that employees have in general, a strong female leader comes off with a different connotation than a strong male leader does and you know making hard decisions and communicating difficult, having difficult conversations is sometimes clouded by that perspective that exists. And I again, as a leader and as a female that part of that is recognizing and adjusting your approach to situations knowing that sometimes you're gonna be perceived differently simply because you're a female communicating instead of a male communicating. And again I think it's just a reality that, it needs to change but I think that what you do right now is you recognize that's the way it is and you make changes so that you can accommodate those perspectives and that's how I've handled it.

Nell's journey to executive leadership was stepped, with a traditional family upbringing and after raising her own family first; she went back to school and gained practical experience in public and private sector accounting. Echoing this sentiment, Maren emphasized, "When we're leading, and we're leading effectively, and we do things that men do every, single day, and when someone doesn't like it, they call us the "B" word." She explained further:

But they're very astute, right? Men are astute when they do things like that. They have all this business savvy, and they're so effective, and they're moving the organization forward. But once they get mad at us for doing the same thing, for whatever reason, then we're the "B."

Maren has a strong voice and is a proactive advocate for minority students. Joan has extensive experience with large corporations and has keen business acumen. Joan, remembered advice from a professor warning her to avoid being too aggressive or "they're gonna think you're a bitch;" she went on to say that this was traumatizing and deeply affected her communication style. Looking back, she described herself earlier in her career as "too mild mannered and you kinda get walked on if people think you're not 
strong enough." This leader's self-advice was to "be assertive and not worry about that any longer...about how people view you." She said this realization was a turning point for her in her career. Another leader, Sadie, described men as having the privilege of "ranting and raving and carrying on," implying that women leaders do not share the same latitude. Sadie has a strong, tell-it-like-it-is personality, with extensive faculty leadership experience. She has a unique blend of technical and leadership skills with social work sensibilities. For these participants, gender culture and dynamics played an important role in how they believe they are perceived and how they communicate as leaders.

Two participants identified and engaged in communication strategies to leverage against gender bias in the workplace. Maren chose to emphasize the accomplishments of her female and underrepresented colleagues whether through oral or written communication, she purposefully addressed them as "Dr." or "President" to balance perceptions she believed are related to gender. She clarified that in her experience, women leaders are often not given the full credit of their credentials or rank. In contrast, Zoe used her genuine interest in sports to cultivate a better relationship with her male counterparts. She described the practice as tremendously valuable in connecting with them and reports that it has been "very helpful" in her career. Both women found unique ways to respond to gender bias that either empowered other women or deepened their connection to others.

Self-regulation. Two participants explained how they self-regulate by deliberately diluting or flattening their emotional response in their work environment. Hillary had to "work to try to figure out how not to have an emotional reaction." Similarly, Susan noted, “... as a woman, I certainly felt like I needed to hold in my 
emotions." She explained that she had learned to keep her emotions in check. "Not just crying emotions, or those kind of emotions. Even stress or anything like that, I'm pretty even-keeled and known for that." The influence of gender culture for these women was impactful enough to push them to self-regulate and minimize their emotional response as leaders.

Competence. Several participants felt a greater responsibility to perform or work harder than their male counterparts to participate as leaders. Maren stated that she believed as a woman leader, her skills were not given the benefit of the doubt, when compared to her male counterparts - she experienced this as "an additional burden." She explained, "It's really difficult because, especially in this field, especially when you're dealing with the facilities and the custodial grounds and capital projects. They assume you know nothing. And I can't tell you how many times we've completely saved them." As a result of this experience, Maren felt, "If I had to do this whole career all over again, I would've done the bachelors of science in engineering." A degree in engineering is not a requirement for the Vice President of Administrative Services position; typically, the preferred degree is accounting, finance, business, or administration. For Maren, experience with the facilities, custodial and capital projects staff reinforced her belief that her skills were not recognized to the same extent or degree as her male counterparts. The impact of this experience was significant enough for this participant to doubt her choice of formal education, despite it being consistent with normal qualifications for the job.

The self-imposed expectation to over prepare was a burden for some of the leaders in this study. Bonnie explained, "I still feel like I'm in the little boys club, and it 
takes some effort sometimes to not let that become part of your thought process, because there's nothing you can do about it really except be competent." She continued:

[I] tried a little bit too hard to be you know, smart, and prepared, and articulate when it doesn't matter as much as I think it matters, because I just don't want to be seen as someone who shouldn't be at the table when I'm dealing with a lot of men.

Bonnie became a vice president after moving up through the ranks, she actively embraced all professional development opportunities and believes in incorporating humor into her daily practice. This sense of obligation and effort to over prepare represented an underlying concern that her skills as a leaders were not given the same "benefit of the doubt" that her male colleagues enjoyed. The fact that this participant feels it necessary to incorporate this idea into her thinking along with the physical and mental effort to over prepare, represents a burden of competence.

Bonnie, despite efforts to over prepare reported, "I've supervised men very comfortably, had them supervise me, and it's been really comfortable, but I've also felt like it was clear to me that they didn't feel like I belonged." While Bonnie felt that gender played a role in preventing her full access, she also shared thoughts about working with other women leaders. She noted:

I think we hold each other to the same, or even stricter professional standards, but there's an underlying kindness, because I don't know, we're women, and we take care of one another, and I don't know if that's cliché too, but it feels true.

Despite reported efforts to over prepare in an attempt to ensure a high level of competence, these leaders experienced the expectation as a burden.

For the majority of women leaders in this study, the impact of gender culture was a prominent factor in how they navigate their workplace as leaders. They shared insights 
of ways in which they have modified their communication style, altered their emotional response, as well as disclosed feelings of exclusion. These leaders, in spite of the burdens negotiated the challenges of their respective gender cultures to "take care of one another" and be successful.

\section{Service}

Most women leaders, 7 of 12 (58\%), expressed a connection to the meaning of their work, for some that was connecting the fiscal health of the institution with service to students, while others identified a clean leadership process as the greater calling. They reported being motivated and deeply committed to serving students, their institution, and believing in the power of higher education.

Students. Student service and connecting with students was a high priority for the women leaders in this study. Although the core work of administrative services is institutional finance, facilities, human resources and security, these leaders reported an underlying commitment to their work that has been driven by a desire to serve students. Susan stated, "What really attracted me to the community college was the environment, the people, the students, the closeness of students." She went on to say, "I love coming to work every day and seeing the students. It gets really boring in the summer, when they're all gone for a long time and quiet, and you're ready for them to come back." Seeing the students reminded her of the purpose of her work. Susan, a consummate professional, embraced servant leadership, accountability, and put complete trust in her direct reports. Bonnie explained that she is "always moved" when she gets to spend time with student leaders. It reminded her of when she was young: 
.... and motivated, and wanted to change the world, and so I'm always interested, and get a lot out of that spending time with them, and usually it's in response to some request for information that they have or some idea they have that they want to improve the campus in one way or another that they need my direction on how to go about it. So it's usually a positive experience anyway. I do really enjoy that.

Another participant, Zoe, found a way to improve her connection with students through teaching. She articulated, “...it's really rewarding to kind of give back from a standpoint of being in the classroom, teaching the courses, that I took many years ago, now, but kind of a better connection to our students here." Connections with students was also important to Maren who felt especially bonded with underrepresented students and said, "...to be able to work with them and see them move on, write letters of recommendation, it was just really impactful, and I just loved it. I just absolutely loved it.” Several participants spoke with a protective tone of their role and their goal to maintain a student focused mission, drawing a direct line from their work to serving students.

Institution. Leaders in this study shared the belief that the community college as an institution exists to serve students and all roles support that service. When focus veers away from students, Maren described, "It breaks my heart when my colleagues talk about students getting in the way." She saw everyone's role at the college as essential and..., “when they fight and argue with their colleagues. It breaks my heart when they don't see themselves as integral to student success, when they're just focused on financial control." Another participant, Hillary, also tried to avoid the "arguing and bickering over money," and shared the same sentiment, "I don't care about the bickering because I care about what's best for everyone." Conflict among executive cabinet members led another participant, Nell to take action. She explained that relationships had deteriorated "to the 
level of where we were almost working against each other... we were working in silos and kind of not helping each other get our work done." She became so disheartened by the working environment and the group's inability to be effective; she disclosed, "I ended up leaving that position." These were revealing and meaningful statements because the primary role of the Vice President of Administrative Services position is to be responsible for the financial stability of the institution; these leaders obviously sought to balance that responsibility as well as the institutions' core mission, along with service to students.

Power of higher education. The women leaders in this study believed in the power of higher education. Maren expressed, "My personal values were just helping underrepresented students improve their conditions to higher education because it's a game-changer for the rest of their lives." She went on to explain, "We are not producing a car or a computer... but we're producing and getting people started in their lives, and it's a great mission." Many of the women leaders purposefully chose a profession in higher education; several had work experience in the private sector for comparison and further explored their personal motivation and meaning making of the work. Bonnie shared, "I really truly believe in higher ed. at all levels...I don't think I could have done it this long if I'd felt like it wasn't a good investment." These executive leaders were passionate about their service to students, the institution, and higher education. Their deep commitment to the success of all three was not only a plain rejection of the accusation that they "only care about money" often ascribed to this administrative role, but it was also a testament to their belief in potential — a crucial foundation of transformational leadership and connecting with others. 


\section{Quality of Leadership Connection}

What these leaders valued and how they connected with others was a notable aspect of their leadership experience. In this study, 7 of $12(58 \%)$ participants highly valued honesty in their role. They expressed a potent faith in valuing the "whole person" suggesting an egalitarian philosophical attitude.

Honesty and integrity. Honesty and integrity in leadership were a salient theme for these leaders. Hillary said, "I believe that being honest is first. That's probably one of my strengths and a weakness." She went on to say that she is not a person who has hidden agendas but she has "worked with people that do that in the past. To me that's almost being dishonest. I like to be upfront about things.” She believed one can still, “... hold true to honesty into your values and still work in a political environment." She recognized that practicing leadership with a high degree of honesty and integrity can be a competitive disadvantage with respect to politics, but chooses to do it anyway. Nell shared a similar sentiment that she strives with her peers and colleagues to "...have open, frank, honest conversations even when they are in, we're in disagreement, but to be honest and respectful and try to come to consensus on decisions and support them when they need support." Susan said that honesty and integrity are part of her value system, "I think that comes across in everything I do, by my actions and my words, and definitely expect that from my directors. I expect it from my boss as well." This leader was working to live by her value of honesty and was consciously modeling it for those around her. These participants cited honesty and fairness multiple times; they came with substantial work experience in finance or accounting and seem to link this degree of 
transparency to the ethics standard of the discipline but also as a foundational quality of relationships.

Valuing the whole person. These executive leaders appeared to be driven by an egalitarian philosophy. They believed that all people have value, diverse talents, and that the "whole person" should be appreciated. Hillary gave an example of the custodian group in her organization, she reported that she tries to let them know that she appreciates and values their work as custodians. She advocated actively for their salary increases. Another participant, Sadie, recounted her disapproval of statements like "from the custodians to the president." She reminded people to think about what message that sends to the custodians. She said, "I come from a family where the basic belief is everybody has value. So, when you get in a job like this, you have a lot of empathy for everybody.” Even when there is disagreement, Nell said, “...there's value that can be gained if you have a mind that allows for that." She went on to say, "What I've learned with leadership is that you really have to value the whole person and everyone that you work with or who works for you has value." Nell explained that she tries to model an acceptance of people's talents and along with that comes flaws, no one is perfect... and that it is "part of the whole package." When Morgan reflected on her career, she said, "A lot of it has to do with respecting the people that I work with and that work for me and recognizing that, you know we all have different talents and they're all very good." Morgan began her academic career as a returning student; she is an entrepreneur who started her own business before moving into higher education administration. She was frequently chosen for leadership roles from an early age. The leaders in this study 
believed that all people are equal and that the "whole person" should be valued - this belief was apparent in their approach to leadership.

Gail demonstrated her belief in her actions; she shared that "when something needs to get done be able to roll up sleeves up and pitch in as part of the team as a worker and be alongside folks so that they don't feel like you're separate or above something." She stated that it is important to "look for those opportunities ... so that your team, so that you really truly are working as a team with the people you're trying to lead." She believed by engaging with her constituents in this way, she was creating an environment that would foster respect and value everyone. Gail, a self-described introvert, demonstrated an altruistic orientation.

When a high degree of respect is present, Morgan believed there is “interconnectivity, that -I will hang my hat on that. I really do." She observed, "I kind of go back to this relationship being softer, boy, that flower opens up and you can see the middle of the bloom and it's all - the petals are all working together." She reported that if she reverts to a command control style because something needs to be done immediately. She recalled:

It's just so amazing how the team kind of recesses into their own shell and it's like, oh, wait a minute. I'm moving away from that interconnectedness, that relationship building, and I need to get back on track with that. And then my team comes right - you know it's kind of like a flower, right? Command control that flower is sucked up and no getting, no seeing the middle of the bloom.

Morgan described an almost give and take style of power sharing that is born from nurtured relationships resulting in an "interconnectedness" among her team. These executive leaders noticeably valued honesty in their communications and interactions, and expressed a preference toward an egalitarian approach. They consistently found 
value in the whole person and reported the quality of the connection to be of extreme importance to them personally and vital for a healthy and productive workforce.

In the next section, I describe and explain the ways these leaders self-reported the use of transformational leadership practices.

\section{Vice Presidents and Transformational Leadership}

The women vice presidents in this study reported using transformational leadership practices. I used the Kouzes and Posner (2003) model to inform the analysis and help to define the result.

How do women administrative vice presidents self-report the use of transformational leadership practices? Using Kouzes and Posner (2003) theoretical framework of transformational leadership for analysis of interview data led to the identification of four personal leadership practices (a) model the way, (b) inspire a shared vision, (c) challenge the process, (d) enable others to act. Analysis of the data did not indicate that the fifth practice, encourage the heart, was a significant practice for the women vice presidents in this study.

\section{Model the Way}

Model the way is the first of five transformational leadership practices and includes two behaviors, "clarify values by finding your voice and affirming shared ideals" and "set the example by aligning actions and shared values" (Kouzes \& Posner, 2003 b, p.4). In this study, 7 of 12 (58\%) participants reported using the transformational leadership practice of "model the way." Three of the participants noted clarifying values by finding their voice. Bonnie knew she would fully accept her executive leadership role as evidenced in her reflection, "I must really have this job now, because now I'm 
mentoring someone else." Similarly, Joan spoke about her transition, "You're looking for other people for guidance for and then we realize, well hey, we're right there at the top. It's us. We have to step forward to really be those leaders that we need to be." She said, "You may feel terrified inside, but you really have to have calmness." Sadie echoed this idea, "When you really don't want to stand up is when you have to stand up..." For these participants, finding their voice was a memorable and important step in their development as leaders.

Other participants gave testimony consistent with "setting the example by aligning actions and shared values" (Kouzes \& Posner, 2003b, p.5). Zoe stated, "I was able to show that integrity through my actions... and make sure that $\mathrm{I}$ - if there is a misunderstanding of anything, that I correct - I quickly address it." Joan demonstrated her integrity by articulating her reasoning as it relates to decision-making; she said, "You have to be able to give a good explanation sometimes for why you did that, and then you have to follow through and not waffle." Another participant, Vicki was very deliberate with her intention to set an example and shared, "I certainly model it. I certainly talk to peers about it and encourage the approach...I know I've had some influence of people." Vicki has held a variety of leadership roles, is an intellectual who likes challenges and is professionally outgoing. Many participants self-reported the use of model the way in their leadership practice. Nell summarized it best when she said, "I have found throughout my years that you can get people to look at you as a leader not by telling them you're a leader but by showing them you're a leader." These leaders actively sought opportunities to be consistent with word and deed; in doing so, they were teaching their constituents and colleagues how to model the values of the institution. 


\section{Inspire a Shared Vision}

Inspire a shared vision practice is defined in two ways: (a) envision the future by imagining exciting and emboldening possibilities, and (b) enlist others in a common vision by appealing to shared aspirations (Kouzes \& Posner, 2003). In this study, 7 of 12 (58\%) participants reported using the transformational leadership practice inspire a shared vision.

For many participants, communication was critical to the creation of authentic employee teamwork and buy in. For example, Zoe said, "Honestly, one of the most important things is just communication, and being transparent in how you make decisions. The type of input and feedback that you provide is so important for employee buy in." Similarly, Morgan stated, "It's definitely getting the team concept going. And getting buy-in from not only my direct reports but that they're getting buy-in from their direct reports so that my whole team feels like everybody has a voice." She described her staff and others on campus when she said, "Everybody knew they had a voice... it's always been collaborative." Bonnie conducted weekly individual meetings with her direct reports and weekly staff meetings so that she "...can share information from the top, and they can share information from their areas, and then we can really work together as a team ... we've worked hard to be a really strong team." Vicki emphasized the importance of removing barriers for her employees to fully engage in a shared vision. She said it was very important for her, "to have everyone who works for me understand that what they do matters. I don't care what level you are in the organization. That is not a measure of contribution. It takes all of us to get it done." She went on to say that she learned through experience the importance of the relationship between a vision and 
having a happy, healthy workforce. In an effort to connect her employees to the vision, Joan asserted, "...these are things that we have to achieve, and how can we do that with the resources we have? How can we help each other? How does it tie in to something maybe going on at a larger level?" Morgan explained that her employees recognized how she conducted herself (with an emphasis on fair and equal treatment in her service philosophy), she said, "And then we started talking about it. ... And they could see it. But I wanted them to actually be able to articulate that in how they were doing business." Last, Sadie explained that she tries "to remind people of the mission that they want to be on ...the path they want to be on" to bring them back to the shared vision." By asking purposeful questions and stimulating how employees think about values, these leaders helped orient employees to personify and engage in a shared vision.

\section{Challenge the Process}

The transformational leadership practice, challenge the process, is defined in two ways, (a) search for opportunities by seizing the initiative and by looking outward for innovative ways to improve, and (b) experiment and take risks by constantly generating small wins and learning from experience (Kouzes \& Posner, 2003). In this study, 7 of 12 (58\%) participants identified experiences consistent with this practice. Four of these seven leaders reported "learning from experience,", most using the word, "mistake," and only two reflected on experiences that represent "generating small wins" and "by looking outward for innovative ways to improve."

Sadie spoke about making mistakes as a form of accountability, "If I make a mistake, I admit it. The best way to stop making mistakes is to make yourself admit it and it really sucks to actually admit it." Several participants talked about the value of 
making mistakes. Maren said, "You learn from failure, too. You learn things that you shouldn't do and that you won't do again, and you learn how to fix your mistakes." Zoe also viewed making mistakes as an opportunity for improvement; she said, "Taking those learning moments and just being able to reflect on them, how would I do something different in the future?" Nell reported on the value of learning from mistakes as a leader and a key message that it sends to constituents and said:

Admitting when you make a mistake is huge for a leader because we all make mistakes and it helps others to understand that their mistakes are allowed, that it makes you human, that it's totally acceptable, that we learn from our mistakes, that we need to learn from them, we can't keep making the same ones over and over. But I think that's the other thing is allowing my employees to come to me and say, "You made a mistake here," or "this decision isn't the right decision."

Nell had a unique perspective on how she uses feedback, "Yes we need to accept constructive criticism and look to improve the things that maybe are weaknesses in ourselves but that doesn't mean that we've lost any value." She was able to process and synthesize feedback and used it to improve without the change negatively affecting her sense of contribution or "losing value."

Two participants, Hillary and Vicki, provided examples consistent with "generating small wins" and "outward innovative ways to improve." Hillary described a time when she was working with an all-male negotiating team who had adopted a winlose debate style. She was able to influence the group saying, "Let's do what we can do and be patient versus immediately pouncing at everything that they say," pointing out the mixed gender of the opposing team and how the win-lose style might be received. This participant identified her being female as an advantage, bringing balance to their team and adding perspective to their approach. Recalling a challenge, Vicki said, "It was just 
always a little tougher to get things done in that way just because things were a little bit more bureaucratic and cut and dried." But she was successful in her ability to influence a large group of professionals with a formal presentation. She continued, "We actually ended up with a full house. And people walked out enthused." Attendees at the session shared comments such as "I mean it's really a great idea and I'm really inspired. I'm really ready to go back and try this. You know. So that was very gratifying." For Vicki, sharing the information was an outward way to improve while the response and feedback was a win.

\section{Enable Others to Act}

The "enable others to act" practice is the ability to foster collaboration by building trust and facilitating relationships, and strengthening others by increasing selfdetermination and developing competence (Kouzes \& Posner, 2007). The majority, 11 or $12(92 \%)$ participants in this study reported behaviors consistent with this leadership practice.

The executive women leaders in this study expressed a deep sense of caring for the personal and professional well-being of their employees and colleagues. Their statements revealed a deliberate effort to build trust and strengthen relationships. Zoe said, "It has been strictly by building relationships, communicating, being very honest and up front about financial situations... That's been probably my number one thing is just open communication, transparency, and providing good financial information that's reliable." She reported receiving consistently positive feedback for her approach. Hillary said that she was able to manage relationships in a "fairly effective manner" and that she had "good relationships with the people that reported to me...building relationships not 
only with the individuals I worked with, but then also with the board members, the presidents." She shared a specific time when she was able to give from her budget to fund a position in another department, it made her feel good because she was able to help people outside her department and that "hadn't been done before." Joan found success in building trust and facilitating relationships by asking, "How can I help you?" in a genuine way to her direct reports and colleagues. She said, "I always learn something usually from it." She went on to say that the answers she receives help her to gain new insights into barriers or challenges faced by her employees or service issues experienced by her colleagues. She asked the question, how can I help you, sincerely she says because, "I want them to be successful." Joan used this method to foster better relationships with new executive team members and reported, “They've got some challenges, and just the challenge coming in a new environment, and so part of my goal is really try to impart that institutional knowledge I have here." Joan was clearly invested in the success of those around her.

Other participants expressed their investment in relationship building with a focus on supportive and encouraging messaging. For example, Hillary noted, "Having them know that I have a genuine and authentic interest in them as people and in their personal growth and development and their well-being." Joan reported saying to her direct reports, "This is your role in this and this is what I'm gonna do to support you...I know you can do this and I'm always gonna have your back." Morgan believed that "letting people kind of play to their strengths and not focus on their weaknesses" is a good way to develop trust and build relationships with her employees. Five participants mentioned listening as an essential feature of maintaining good relationships. For instance, Morgan 
said, "The fact that I listen to feedback from people." Bonnie prioritized listening because without it "there are just too many unintended consequences when you don't hear what people's real issues are, not necessarily just the ones they tell you, but what their real issues are." She said she'd learned to be patient and to "...let people tell me in their own way, and through their own processes what it is they want to achieve, and then I can help." Nell had a similar viewpoint on building trust and explained:

Listening to people that I'm leading and encouraging people that are reporting to me to be open and honest and in providing me with constructive criticism. Because again I'm not perfect either, so I, you know, in the whole area of performance evaluations, asking people to provide upward evaluations and trying to create an environment where employees feel like they can communicate disagreement without consequence.

Zoe also found power in listening, she reported, "The best I can do is to try to change that person's patterns in a supportive way and then also listen to those that are impacted and try to improve it." Whether she was leading a meeting or working with direct reports, Joan said she tries "to be a really good listener." Servant leadership was the term used by Susan to characterize her core leadership philosophy, which means, "being there to support and facilitate so that my directors can do what they need to do." For all of these participants, listening and a genuine desire to help was foundational to the development and preservation of trusting relationships.

Many participants reported examples of "strengthening others by increasing selfdetermination and developing competence." Morgan spoke about how she worked with a new employee who needed supervisory skills, "I truly spent that first year working with him constantly to help him be a better director... it was all about him, it was all about helping him be successful." Another participant, Maren, spoke about helping employees 
develop professionally. It was her responsibility to approve request for continuing education (tuition reimbursement) and she used it as an opportunity to check on them. She reported asking, "How are you doing, I saw your thing come through. Are you on target? When are you going to be done, What are you thinking about afterwards?" Maren recounted a story of a young professional who had been successful in the accounting department and enjoyed the work; yet after meeting with a counselor followed the advice to pursue a transfer degree in psychology. When she learned of this decision, she went to him and said:

It's been bothering me that you went to psychology cause you're all about business so I want to talk to you about business... I know your love of basketball. I know your love of sports. I want to talk to you about doing business for sports.

He said he had not thought of doing business for sports and was interested in learning more. Maren viewed this interaction as a successful example of strengthening the employee by increasing his self-determination and competence.

Another participant, Vicki, shared a story about a study initiated and coordinated by the custodians of her institution with external benchmarking to test expectations (e.g., cleaning a restroom in ___ minutes). She actively supported them and the director in this effort:

... now [they] have a much better sense that what they do is an actual profession and a discipline and there is a measurement behind it and there's good work practices and bad work practices. And so if I would say even if they don't want to advance, they have developed new found respect for what they do all day. As a profession. In addition to the contribution it makes to the college.

Peggy described a time when a new piece of equipment was needed, so asked the employee group how it was going to work for them: "What can do we to make it okay?" Initially their response was “... whatever you decide to do we'll make do." She said, "No, 
you should have a voice in this too." This interaction demonstrated her effort to empower and strengthen her employees. Peggy describes herself as not social and "not your boss" type of leader. She values the human side of her leadership work even though she loves working with numbers.

Several participants spoke more generally about ways they enable their employees. For example, Susan said:

Being a facilitator to help those that work in your group, accomplish the tasks that need to be accomplished, to serve their constituents, to grow as a person and as a leader themselves. So, helping them find the tools, breaking down barriers, helping them solve problems.

Nell has tried to help people to "really look at what they want to achieve and help them identify the things that they need to do to get to their goals." Sadie said she tries to help "them make the decisions to the best of their ability...working hard to support them, and to encourage them, and not to be reprimanding all the time...trying to help them find their own footing so that they feel real comfortable." She wanted them to come to her with solutions. Thinking about the process of developing relationships and strengthening her staff she said, "They just had to trust that I trusted them to do their jobs." Maren connected enabling her employees to her own success; she reported "empowering them, giving them their tools to make sure that they have the tools to be successful, and identifying what their skills and abilities are so that you can be a better leader." She explained that she constantly challenges herself to learn more, to leverage her employees' skills so that she can better serve.

Enabling others through building relationships or strengthening self-determination in others was extremely important for these executive leaders. Their examples 
demonstrate the variety of ways in which they cultivated trust and created a sense of interdependence among their constituents and colleagues.

The majority of the participants, ranging from 7 to $12(58 \%-92 \%)$ reported behaviors consistent with four of the five leadership practices (a) model the way, (b) inspire a shared vision, (c) challenge the process, and (d) enable other to act. The fifth practice, encourage the heart was not determined to be a significant practice for these women leaders. According to Kouzes and Posner (2003b), transformational leadership is guided by the notion that there is a relationship between leading and learning. The skills widely used by the participants in this study were honed and developed throughout their careers. In the following section, I present the results regarding how these leaders learned to lead.

\section{Learning to Lead in the Community College}

Opportunities for women administrative vice presidents to learn leadership were abundant. I identified four themes in the data that represent their most significant avenues in learning leadership.

How have women administrative vice presidents learned to lead? In this study, the executive leaders found the most impactful experiences were through connection with mentors, leadership observations, accepting additional duties, and networking. The presence of mentors provided these participants with encouragement, support, guidance, validation, and training. Their leadership development was shaped by observations of both effective as well as poor leaders. From these experiences, they gained insight into their own strengths and the leaders they wanted to become. Exposure to additional responsibilities allowed them to gain new skills, challenge their continued growth and 
knowledge base. Many relied on networking for problem solving and as a vital connection to colleagues, especially other women executive leaders. Learning to lead was a journey for these executive leaders.

\section{Mentoring}

A majority, 10 of $12(83 \%)$ participants expressed that having mentors was a positive and key aspect of their developing leadership skills. These participants affirmed that mentors were helpful in a variety of ways including learning new skills, general support, and in the pursuit of career advancement. A smaller group of four participants mentioned being a mentor to others.

The opportunity to learn new skills and reinforce the application of those skills was an important mentoring experience for Hillary who said, “... the next supervisor, she mentored me along the way and so I learned how to work on the budget and work with the board of education there." Hillary also shared, “...he asked me if I would take on the role of the budget officer, and what he did is he worked with me individually, and sort of reminded me of all the things I already knew."

Vicki found success by actively searching for mentors and reported several benefits from the relationships. "I always sought out mentors, although, honestly, I wouldn't have called them that at the time. But people who were interested in taking an interest in me. And dealing with my insatiable curiosity." This participant went on to say she ended up with new opportunities as a result of her mentor. She discussed the change in perspective she had gained from the relationship, “...I also had the opportunity to go to some conferences and kind of learn a bit more about being a professional in the workplace. You know develop a higher order perspective on the work I was doing." 
Vicki emphasized a lesson learned from her mentor on the power of leadership to create a culture of a good work and life balance. She shared:

... that was certainly made possible by the environment that he created. So it allowed me to see that you can create a world, you really can, when you're in that leadership position. You know. So if you want it to be a certain way...

As a result, she explained that she experiences "close alignment in my work life where the distance between who I am at work and who I am when I'm not at work is not that great here." She credited her mentor with creating that culture.

An inspirational and supportive mentor was essential for Joan who reported, "I tell you, she was probably the best woman leader that I've seen in how she dealt with tough situations and how she really motivated people to really get a lot of really difficult work done." She went on to discuss the significance of having someone with whom she could have supportive and confidential conversations. She noted, "If you have that person that you know that you can talk to, and that you can bounce ideas off, and you know you're not gonna be punished in any way, that just really allows people to really blossom and move forward." Joan's trusting connection with her mentors was critical for her how she progressed in her career learning valuable lessons along the way.

Mentors were a key feature for several participants in this study with regards to career advancement; Morgan reported receiving this feedback as a job candidate: "You did a great interview. Please don't give up. Please keep moving forward. Please keep doing this. So I had this person that I didn't really know was almost kind of really encouraging me to keep trying." Maren reported her mentor giving her advice about her future; “he said, 'So I don't want to see you stuck. I want you to apply. Even though I don't want you to go, I want you to apply elsewhere and know that we will give you a 
good reference.'" Mentor support also made the difference for Zoe who said this about her transition into the Vice President role "...ironically it was as a result of one of my best mentors who knew about this - a vice president position here" She continued, "I would not have made the move here to [ ] without that mentor encouragement, because I had every excuse in the book of why not to apply." Zoe identified the decision to accept the position as pivotal and positive in her career.

Three participants expressed how mentoring others was a value. For example, Bonnie found herself and her mentee connecting personally, sharing their experiences. She reported, "Where we have things in common, and where we have completely different perspectives, and so I think I learned a lot from her the same as she learned from me. That was rewarding." Another participant, Nell, considered the meaning of mentoring in her professional practice; she said:

I think that's part of a leader's role is to look at others that are up and coming leaders and identify those people and then help them to become, to achieve their potential. So that was what was done for me and I have always tried to be in that same role for others who have worked either directly for me or indirectly, that have chosen me as a mentor or asked me for guidance.

Other participants reflected on mentoring conversations they had with individuals in their staff and through connections with underrepresented students. For most of the participants in this study, mentoring had an influential role in learning new leadership skills and as a resource for support and in career advancement.

\section{Leadership Observations}

For half of the participants, 6 of 12, observing leadership in action both good and bad, was fundamental to their leadership development. Zoe said: 
And so I had a lot of opportunities to see other leaders in action. Some of those leaders were really good. Some of those were not as good. And so I learned, I think, as much from the really high quality leadership examples as I did from the really poor examples saying, "I don't want to be like that."

Some participants were deeply affected by negative leadership observations and spoke about how this experience influenced their own leadership philosophy and practice. For example, Sadie said, "[they] almost destroyed this place. ...that was a bad hire. ...But under [them], [they] made it so miserable, there's no way I didn't do that. So, when you have somebody like that around, you really learn a lot of things you never wanted to know." Zoe expressed a similar sentiment:

...because it was so stressful, so incredible stress. Yeah. It's hard to describe the level of stress when there's that type of leadership undermining that takes place with even just if it's a few individuals, it's extremely difficult to counteract that, and you're constantly having to work on reputation damage control. That's really the way I looked at it. And that is extremely draining.

Poor leadership and its consequence for employees left an impression for Joan who said, “I think sometimes I've seen really poor leadership, and—where people are—-they're not empowered, or else they're treated poorly. And so that is - that's not my style; I don't wanna ever do that."

Participants who reported learning leadership through observation made more statements about "good" and/or "bad" leadership while only one alluded to gradations of leadership quality. Vicki recalled, "I've seen leaders that I thought were good and effective and I've seen leaders that I thought weren't good or effective. And I aligned myself with the demeanor and behaviors of those that I thought were effective and good." Morgan said: 
I've been able to talk to some really amazing leaders. And I've also been able to talk to some leaders that I didn't really like the way they led. But I think there's a lot to be learned from why they are leading the way they lead, right?

Leadership observations for these participants had a lasting and influential impact on their individual leadership beliefs and behaviors.

\section{Accepting Additional Duties}

Participants noted that accepting additional duties were central to learning leadership, providing opportunities to learn new skills. In this study, 9 of $12(75 \%)$ participants reported that they volunteered for additional duties, actively sought them out, or did not decline when opportunities were presented. When Maren's director asked who would like to try to do the "financial stuff," she replied, "I'll do it, I'll try to do that." She said, "And, so I got to do that." She spoke about trying new tasks in a positive light and said, "When I was in different professional roles, taking on responsibilities that weren't within your job description and taking leadership roles prepares you." When Sadie volunteered to join an accreditation project, she reflected that the experience gave her a "much more of a global view. And, then, of course, when I did this Continuing Improvement process, I worked with everybody." A few of the participants pursued opportunities to take on new challenges. Hillary said, "I always wanted more responsibility, and I'm not quite sure why, but I just felt like I wanted more responsibility than what I was doing at the time, and I enjoyed it." Bonnie felt seeking more responsibility was a natural progression; she explained:

I supervised the same group of people, plus a couple of more. So it was just kind of the next step. A little bit broader responsibility and I went for it because I felt like I had such a great team I could easily take on a little bit more responsibility, and it would be a support in the work, and it worked out great. 
Vicki reported the same desire, "So I've always been motivated to seek additional responsibility. Always. Again, as long as I can remember. ... And then from there it was just a matter of always seeking new challenges and always seeking additional responsibility." This participant clarified that she was loyal to herself with regard to new duties "... and doing that in the context of a job I was interested in." While some participants enthusiastically sought new duties, others simply accepted that the practice has value. Nell said, "I didn't really want the extra work, I don't really have an affinity for human resource issues, especially when it comes to unions and union negotiations, but I said, "Okay I'll take it on." She went on to say that she learned a lot by taking on that role and that by accepting it and others after she reinforced a successful learning practice. Susan reiterated that she "never said no to an opportunity." Taking on additional duties was beneficial for the majority of the participants in this study. They reported a benefit from exposure to opportunities to learn new skills and a favorable habit of challenging themselves to grow. Hillary summarized, "I'll learn something, and that's how I've come on every single thing I've done, is that, "Well, I can learn. I will learn something from this. There are lots of tears at times. I'm not going to say I never cried about it." Challenging but rewarding, new responsibilities brought opportunities to learn and pushed their continued growth as leaders. These participants also found value in connecting with like-minded executive leaders through networking.

\section{Networking}

Most participants, 8 of $12(67 \%)$ reported a strong appreciation for and use of networking. The term "networking" was used most often to describe the formation of a connection with other professionals who share similar responsibilities for the purpose of 
problem solving, learning, and support. For example, Zoe summarized the value of networking as something, “...that's been extremely beneficial from a leadership standpoint. We're very closely connected to our colleagues among all of the community colleges. That's invaluable." From the standpoint of problem solving and consulting peers to brainstorm solutions several participants agreed that networking plays a vital role. For example, Sadie remarked, "I have all these colleagues that are doing the same job or a lot comparable jobs that I can call up and say, "Okay, what are you doing with this? Help me out with this project." Similarly, Susan asserted:

Networking just in my professional organization, and that's with both women and men, but that are in my similar position, where I'm able to find out how they do something, or how they've handled a challenge, or a problem, or get a reference. That has been very helpful.

Likewise, Vicki stated, "It's worked for me more on the level of work friendships and professional friendships so that I could call somebody and say, "Have you been up against this before and what did you do?" As well as by Bonnie who said that she relies on her colleagues at other campuses, she has gotten to know them personally through trainings and social activities, saying that networking is "very important."

Several participants identified learning as a direct benefit to networking citing exposure to new people, perspectives, and issues. For example, Joan volunteered to take a leadership role within a state-wide work group saying:

....so I have tried to step up that way...It's networking in a way, 'cause what you do is you're exposed to a different group of people sometimes within different topics, and so it's a learning environment. And you do network... 
She went on to say that she had, "met a lot of really good people that way." For Nell, learning was an important component of networking for herself as well as her staff. She said:

I would say in this system because we need to work together and because we learn from each other it has been a huge, huge, huge benefit and I try to tell all of my folks who have similar situations.

By making an effort to get more involved and reach out to others, these leaders continued their learning leadership trajectory.

The use of networking as a means of support was cited by several participants including Nell who said:

... putting yourself into the situations where you're maybe not familiar with people, you're having to be the new person on the block so-to-speak. It can be a little intimidating, but I think it's really important and I think it's invaluable because again it just provides you with resources....

Anecdotally, several participants mentioned their natural tendency was to stay behind the scenes and self-identified as introverts in this respect. Despite this belief about themselves, many noted the value of creating and participating in networking opportunities. Knowing who to call is especially important with confidential issues. Susan spoke about using networking for this kind of support and said, "I don't want to say 'complain' with, but if I'm going to complain about something in my job, I'm not going to do it with anybody here." She went on to say she is "... going to do it with somebody I trust, where I can bounce things off of, where it's confidential." Having a safe place to confide in others was an invaluable benefit of networking for this leader.

For Vicki, networking was also a way to connect and find support specifically from other women, she said, "It's been more just the informal support and then just the 
ability to have good conversations, again, with most women just, again, because we tend to be more verbal and just easier to talk to often than men." Networking was a leading theme for the participants of this study whether they relied on it for problem solving, to learn a new skill, or as a safe place for sensitive conversations.

Understanding how women executive leaders experience leadership is important to finding pathways that support their development, inform aspiring leaders, and the development of strategies for institutions to cultivate future leaders. Most leaders in this study agreed that mentoring, leadership observations, accepting additional duties and networking were dominant features in their learning leadership experience. One participant, Sadie shared, "What you come to in a job like this really is everything is learned. You can learn this job. The hard part to learn is that human interaction, and valuing everybody, and not getting upset over piss ant things." Many leaders revealed a natural tendency to care about others, expressing a strong connection and deep investment in their success, an equally strong number reported challenges in doing so, for example, some burdens mentioned were gender culture and respective accommodations, a need to change their personal style of communication, and suppressing emotions in the workplace. In spite of these challenges, the balanced perspective (i.e., people and finance) these leaders bring to their work and their unwavering commitment to service make each of them an impressive and transformative asset to the community college leadership ranks. 


\section{Limitations}

In this section, I describe the limitations of my study. Specifically, I describe my assumptions, perspective as a researcher, and limits of the study and analysis.

\section{Assumptions}

This study is based on humanistic values that include (a) an effort to understand participants in context and from a holistic perspective; (b) an acknowledgement that each individual is unique and should be respected; and, (c) that human interactions should include as its foundation — fairness, respect and equity (Patton, 1990). An important assumption of this research is that "understanding emerges most meaningfully from an inductive analysis of open-ended, detailed, descriptive, and quotational data gathered through direct contact with... the participants" (Patton, 1990, p. 119). While intending to align my approach with these ideals, limitations, as with all research remains a reality.

\section{Researcher's Perspective}

I am a 44 year old, Caucasian female. I come from a middle class family in a small community. My father is a retired civil servant and electrical engineer and my mother is a retired early childhood educator in the public school system. For more than 16 years, I was a higher education administrator in public two and four-year institutions. As a former community college employee, my assumptions and personal experiences contribute to my interest in the topic of women's leadership and shape the lens by which I observe other women's experiences, consciously and unconsciously. While I made a conscious effort to maintain an objective stance, I also acknowledge the potential for unconscious impressions and the impact they may have on this study. 


\section{Limits of the Study and Analysis}

This qualitative study includes women administrators in community colleges in the Western United States at a specific time in their career. This study is limited to this point in time and the participants' own self-perceptions. Leaders at the senior stage of their career are both advantaged and disadvantaged by their experience, in the sense that they have a long career from which to reflect on their professional life, but time can also dilute or amend memories and create a falsely positive or negative impression. It is outside my control as the researcher to evaluate the authenticity of these reflections. Additionally, my role as the researcher studying leadership could have effected how the leaders chose to respond, possibly enhancing aspects of their leadership stories.

For this study, the participants who self-selected represent a group of leaders who have achieved the status of executive level leaders in administrative services. This study did not include middle managers or women who might have aspired to become Vice Presidents of Administrative Services and were unsuccessful. Their perspectives might also have contributed to a more complete picture of how women experience the path to leadership specifically in the area of administrative services.

Participants were limited to those who self-selected to take part in this study. Those who chose to participate were willing to share their personal stories including successes and challenges. Other executive leaders who chose not to volunteer may have different experiences that could alter the data and the outcomes of the research.

Limited by geography, funding, and logistics, I conducted participant interviews by phone. Interviews conducted by phone might limit the ability to build rapport with participants. The lack of feedback in the form of body language available in a phone 
interview compared to a face-to-face interaction could have negatively influenced the participants' willingness to discuss confidential or controversial issues.

The semi-structured interview format may lead to ambiguity that varies by individual interpretation. Many factors can influence how a participant processes a question or engages in a dialogue. The flexibility that the semi-structured interview format permits a researcher could also have been a limitation in this study, as each participant dictates her r own direction and level of disclosure.

The small sample size is another limitation of this study. Of 21 women leaders identified, only 12 agreed to participate. For many community colleges, the institutional size and organization determine whether the college can support a Vice President of Administrative Services position. Further limiting the pool is the number of women leaders who hold the position. For purposes of privacy and anonymity, I will not reveal the specific number of women of color who volunteered for this study. In general, the pool of women leaders with this title is small and for women of color, it is even smaller. Additional leadership experiences and insights from this population might have enriched the results and created a more complete picture.

The participants in this study were from four western state community colleges; they may not be representative of the region as a whole especially given the multitude and variation of cultures within this area of the United States. It is the goal of community colleges to reflect the community and an additional limitation is the generalizability of these results to other women leaders as the cultural context of communities themselves is so variable. Along this line, the results of this study might also not be generalizable to other facets of higher education such as four-year colleges and universities. My review 
of the literature suggested that women's leadership experiences are different in community colleges than in four-year institutions (Outcalt, 2002; Townsend \& Twombly, 1998).

The Vice President of Administrative Services position is unique with responsibilities that encompass the business aspect of the college and therefore it should not be assumed that results of this study are generalizable to other vice president roles within the college. Additionally, depending on the size of the institution the responsibilities of the position can vary, for example some vice presidents are responsible for human resources while others are not. Variability in responsibilities could be a factor in how women leaders experience the position.

I made the LPI available to all of the participants of this study. While I expected to receive more, only three participants completed and returned the inventory by email. The LPI was not a requirement for participation and offered as a thank you, and a likely explanation for the low response rate. The data gathered from this inventory and the corresponding comparative results do not represent the majority of participants.

Lastly, in qualitative data analysis accuracy in data interpretation is dependent on the researcher's skills. A possible limitation of the analysis in this study is my own level of experience as a researcher. As a new researcher, my ability to analyze and interpret data could be a limitation when compared with an experienced researcher who may have applied a higher level of sophistication and complexity to the data analysis.

\section{Summary of Results}

The purpose of this study was to explore some of the factors that contribute to women executive leaders' success. I analyzed and presented data to address three 
research questions: (a) how do women experience leadership in administrative vice president positions in community colleges?, (b) how women vice presidents self-report the use of transformational leadership practices, and (c) how have women administrative vice presidents learned to lead. I identified themes and sub-themes and used participant quotes as evidence.

Analysis of the first research question, "how do women experience leadership in administrative vice president positions in community college," produced three themes: (a) gender culture, (b) service, and (c) quality of leadership connection. I discussed gender culture in terms of how gender affected their leadership experience. I used three sub-themes to expound on the gender culture theme, including (a) communication, (b) self-regulation, and (c) competence. For the second theme, service, I described the steady drive to serve, and further defined the three sub-themes of service to (a) students, (b) institution, and (c) the power of higher education. With regard to the last theme, quality of leadership connection, I captured two sub-themes, the values they practice, (a) honesty and integrity, and the nature of the relationship these leaders have with their constituents, the second sub-theme, (b) valuing the whole person.

For the second research question, how do women in administrative vice president positions self-report use of transformational leadership practices, I analyzed the data using Kouzes and Posner's (2003) theoretical framework. I identified four best personal leadership practices based on participants' self-report, (a) model the way, (b) inspire a shared vision, (c) challenge the process, and (d) enable others to act. Most leaders, ranging from 7 to 12 , reported using these practices. 
Data analysis on the last research questions, how have women administrative vice presidents in the community college learned to lead, led me to develop four themes, (a) mentoring, (b) observation, (c) accepting additional duties and (c) networking. Most leaders in this study affirmed that mentoring, leadership observation, accepting additional duties, and networking were primary means for learning leadership.

Some of the limitations of my study are the small sample, including any bias represented by the process of self-selection for inclusion in the study and the small number of women leaders who currently hold these positions in the Western United States. I conducted the interviews by phone possibly affecting the degree of disclosure. This study included only women vice presidents of administrative services, limiting the generalizability to other vice president positions within the college.

The results of this study further expand understanding of how women leaders experience leadership in the community college. This insight is important for the identification of strategies to support their development, inform aspiring leaders and to advise institutions on how to develop future leaders in response to the leadership crisis. These participants have revealed themselves to be deeply committed to student and institutional service, life-long learning, and in the spirit of transformative leadership, dedicated to the development of others while serving with a high level of integrity.

In the next chapter, I describe the synthesis of findings including the culture of gender and women leaders' experience in the community college. Other discussion points presented are the participants' perspective on service and its meaning for them with respect to their leadership along with their perception on the quality of the relationship they share with others. Next, I consider the leadership competencies outlined 
by the AACC as these relate to the findings of this study. I conclude this chapter with recommendations and further study intended for community colleges, leaders in general and aspiring leaders. 


\section{Chapter 5: Discussion}

This chapter includes a brief review of the problem statement, research questions, and methodology. I offer a summary of the major findings as they relate to the literature, which I follow with implications and recommendations for future study.

\section{Statement of the Problem}

Community colleges face a growing crisis in leadership. The overall quantity of community college leaders is on the decline (American Association of Community Colleges [AACC], 2012a). However, the representation of women leaders in community colleges has increased more than other sectors of higher education (Valdata, 2006). This upswing suggests that community colleges are the most likely place for women to achieve executive leadership status (Townsend \& Twombly, 2007). Yet, women leaders remain marginalized in the community college system (Townsend \& Twombly, 2007).

\section{Purpose of the Study}

The principal purpose of this study was to explore some of the factors that contribute women' executive leaders' success specifically: (a) how women experience their leadership role in the community college, (b) how women vice presidents use transformational leadership, and (c) how women administrative vice presidents have learned to lead. By exploring some of the factors that contribute to the success of women executive leaders, one intention of this study was to arm institutions with information to support the development of women leaders as efforts focus on addressing the leadership crisis, and inform aspiring women leaders while they make their ascent to the executive leadership ranks. 


\section{Research Questions and Methodology}

I formulated the purpose of this study into three research questions.

1. How do women experience leadership in administrative vice president positions in community colleges?

2. How do women in administrative vice president positions self-report use of transformational leadership practices?

3. How have women administrative vice presidents in the community college learned to lead?

For this study, I did not use the LPI results in the synthesis because of the limited number of respondents. I selected the exploratory qualitative design for its capacity to include an expansive range of contextual variables. The case study framework enabled me to explore the participant leaders via a thorough descriptive process with examination of a bounded system (Merriam, 2009). I conducted semi-structured interviews to gather the greatest detail and depth of understanding of how these participants narrate their most salient leadership experiences in the community college. The interviews were conducted individually, digitally recorded and transcribed. I analyzed the qualitative data through an iterative process and identified themes.

\section{Synthesis of Findings}

The key findings exposed how women leaders experienced the culture of gender, their motivation for service, and the nature of their connection with their constituents and peers. They disclosed personal transformational leadership practices that are consistent 
with Kouzes and Posner's theoretical framework (2003b), and learned to lead through mentoring, observation, accepting additional duties, and networking.

An important finding of this study as it relates to how women experience leadership in the community college is the culture of gender. The gender culture theme represents how the role of gender has affected their experience. The sub-themescommunication, self-regulation, and competence — are recognized as having gender as a root source by the participants.

Many of the participants experienced gender bias and were conscious of how it altered the way they presented themselves and affected how they evaluated their own readiness. "Leadership is a language game, one that many do not know they are playing" (Fairhurst \& Sarr, 1996, p. xi). These leaders were regular players of the language game. Their testimony suggested they were ever mindful of how they communicated and how they were perceived; they identified this issue as a dominant factor in their leadership experience. Typically, leaders in general spend close to $70 \%$ of their time on communication (Fairhurst \& Sarr, 1996), the intensive and focused effort expressed by the participants in this study might well be disproportional to the average.

Some of the leaders spoke about the ways in which they have adjusted their communication style and approach, e.g. carefully monitoring their emotional response to emphasize a neutral affect. They reported heightened awareness around how their messages were filtered through their gender. Alongside these conscious adjustments, many of the leaders in this study described efforts to create work environments that valued relational leadership styles — a finding that aligns in part, with Tedrow and Rhoads (1999) research on "resistance leaders." In that study, resistance leaders made efforts to 
support a relational leadership culture but valued instrumental and relational strategies as complementary. The leaders in this study seemed to emphasize the importance of relational over instrumental behaviors in their leadership philosophy. It is important to note that in Rhoads' study on resistance leaders, the leaders were rarely rewarded with promotions, suggesting that acting in the resistance role came with negative consequences. In both studies, however, the results indicate that women leaders expend significant amounts of energy navigating organizational barriers that are grounded in gender differences.

An additional pressure to perform was voiced by several participants. For example, Maren who believed her skills were not given the benefit of the doubt, compared to her male peers. Likewise, Bonnie, confessed her determination to over prepare to avoid being seen as "someone who shouldn't be at the table." These findings are consistent with Glazer-Raymo (1999), who also found that women administrators often felt that their opinions were not valued and that twice the effort was necessary to achieve the same goals. Comments made by women managers in Young's (2004) community college study indicated that extreme effort characterized by a good deal of self-discipline and determination were necessary to retain their positions. The findings from this study confirm earlier research that women leaders feel their experience and contributions are undervalued.

Some researchers believe there is a close tie between behavioral expectations for leaders and behavioral expectations for men (Schein, 2001), and that; successful leaders are assessed as such more often when they abide by their respective gender roles and language (Eddy, 2010). Ayman and Korabik, (2010) concluded that women leaders 
might benefit from using more androgynous leadership behaviors. Nevertheless, all of these expectations and suggestions limit both men and women in their use and application of certain leadership behaviors and subsequently, leadership driven change within institutions themselves. Women leaders may likely continue to battle against this belief and its subversive nature despite increasing numbers in their representation, until there is a critical examination of the culture and language of gender (Eddy, 2010; Tedrow \& Rhoads, 1999), and a change within the organizational culture of the community college (Tedrow \& Rhoads, 1998; Townsend \& Twombly, 1998). What the women leaders in this study clearly lack is the luxury of being unaware-unaware of the role gender plays in their day-to-day experience. They are unlike their male counterparts, who are not required to battle simultaneously the homogeneity of male administrations and gender stereotypes (Amey et al., 2002).

The second sub-theme, service, was identified to describe and capture the testimony of the participants who found their calling to higher education in the form of service. For many, the underlying purpose for their work was to serve students, the institution and their belief in the power of higher education. This desire to serve seemed to help them transcend their own professional roles and responsibilities to find personal meaning in the value of their work for the greater good. Maren explained that higher education is a "game changer" and praised the value of higher education as a way of "getting people started in their lives." Another leader, Bonnie cited her ability to persist in the work because she thought it was a "good investment." For these leaders, this deep belief also sustained their efforts to support their employees to find meaning and connection with their own work and contributions to the larger cause and institutional 
mission. Statements like, "to remind people of the mission that they want to be on ...the path they want to be on" to bring them back to the shared vision," give insight into these leaders' dedication to the higher purpose of their work and of those they lead. The link between a leader's genuine faith in their work and a connection to the institutional mission is a vital pillar of transformational leadership. According to Bass, (1999), it is this (emotional) link that has the power to inspire higher values, shared purpose and meaning in followers. That profound connection to a higher purpose and the way in which these leaders translated that meaning dynamically to their constituents laid an important foundation for their use of transformational leadership practices.

Transformational leadership incorporates a high level of morality and challenges traditional ideas of power to engage the follower as a whole person (Burns, 1978). Valuing the whole person was an important premise for the leaders of this study—as characterized by the, "quality of leadership connection" sub-theme. This potentially potent engagement elevates both leader and follower - developing followers into leaders and leaders into moral agents (Burns, 1978). Most of the leaders in this study shared this perspective. They embraced an egalitarian leadership philosophy and gave examples of commonplace statements they felt compelled to challenge such as, "from the janitor to the president..." in their fight to remove demeaning language and messages in their institutions' culture.

These leaders chose to act with a high degree of honesty and integrity, even when they recognized the disadvantage operating with this standard can bring in a political environment. In doing so, they demonstrated their consistent commitment to three key areas: (a) their core responsibility as financial stewards of public resources, (b) the 
development of strong relationships, and (c) their desire to create a collaborative environment. It is an easy accusation to make that those responsible for the finances only care about money. This is more than an innuendo when such statements have the power to and often do fuel divisive dialogue between key areas of the college, instruction, student affairs and administrative services. The leaders in this study gave voice to this conflict, their place in it and their desire to restore an ethics standard to the conversation. They recognized the direct impact on relationships this belief can have. The nature of this conflict undermines the very collaboration that is necessary to build trusting relationships and create an institutional environment that is responsive to change.

The collaboration competency put forth by the AACC's Leading Forward initiative (2005) indicated that an effective community college collaborator "develops and maintains responsive, cooperative, mutually beneficial and ethical internal and external relationships that nurture diversity, promote the success of all students, and sustain the community college mission" (p. 6). The leaders' focus on this work is consistent with the tenets of transformational leadership as it relates to building trusting relationships as well as the AACC's standards for leadership.

The focus on relationships pattern continued in the results and analysis of the second research question, how women administrative vice presidents self-report use of transformational leadership practices. The LPI survey results were not included because of the low number of respondents. However, a substantial number of leaders in this study, 11 of $12(92 \%)$, reported using behaviors that are consistent with the enable others to act leadership practice (Kouzes \& Posner, 2007). The features of this practice include fostering collaboration by building and facilitating relationships, increasing self- 
determination and developing competence in others. Developing relationships and supporting the development of their employees was a priority but even more interesting was the manner in which they approached this objective. Many of the leaders spoke about and used the word, "listen," and specifically, listening with the intention of learning. John F. Kennedy (1963, para. 2) asserted, "Leadership and learning are indispensable to each other." The leaders listened to learn and better understand the talents, aspirations, problems, challenges, feelings, and feedback from their constituents and peers. Rosabeth Moss Kantor said, "Leaders are more powerful role models when they learn than when they teach" (Kanter, 1997, p. 56), this statement rang true for the leaders in this study who cited listening as a critical skill and practice in their approach to leadership and overall success.

The women in this study reported learning leadership through four primary means, mentoring, observation, accepting additional duties, and networking. Two of these areas were most prominent -mentoring and accepting additional duties. Many of the leaders, 10 of $12(83 \%)$, identified mentoring relationships as a vibrant feature of their leadership development process. Their mentors challenged them, provided opportunities for growth and actively worked to help them navigate a path to continue their professional development during critical periods. They filled an essential role by reminding some of the leaders in this study of things they already knew when faced with new challenges, responded to and supported "insatiable" curiosity, and demonstrated how to traverse tough situations and still "get a lot of really difficult work done." The leaders in this study found that mentors emerged in their life naturally or through their own efforts to foster such relationships, but the AACC is calling for a more active approach to 
develop leaders within the community college. If successful, this approach could qualitatively alter the development of leaders and leadership in the community college.

In 2013, the AACC published a revised document on leadership competencies for community college leaders. This document acknowledges the need to reset and recalibrate how the system serves students along with expectations for leaders in response to the anticipated leadership shortage. Statements and language like, "Institutional transformation cannot take place without the development and continual improvement of a college's leadership", "dramatic steps - a greater sense of urgency," "deliberate preparation," and “...expectations we have or our leaders are different from past expectations..." (AACC, 2013, p. 2) highlighted an acknowledgement of insufficiency and desire for change.

The AACC called for experienced CEOs to mentor midlevel leadership and maintain the social justice mission of the institution and continued to say that, "members of the community college community can lead from all levels, but must be empowered to do so, (AACC, 2013, p. 5)." The "curriculum must be much more than anecdotal leadership war stories," and must include "opportunities for application of the concepts that the participants are learning" including ... "learning team-building components and networking opportunities... guided experiences" (AACC, 2013, p. 5,). Under the communication competency, the expectation for experienced CEO's is to "facilitate an environment of shared problem solving and decision making" (AACC, 2013, p. 9). The content and tenor of the document reveal as much about the current state of leadership and leadership development in the community college as it does about the vision for its future state. Change is afoot. The AACC's effort to influence a change in the current 
leadership culture and establish programs and processes to create the supportive culture necessary to develop good leaders may serve as validation for those executives currently in its ranks and bodes well for aspiring women leaders.

One commonality among the executive leaders in this study was their attitude toward personal growth. Most of the participants, 9 of $12(75 \%)$, reported that they accepted additional responsibilities, in some cases to fulfill a desire to learn more, while for others it was about increasing responsibility. This orientation toward learning and growth aligns with a growth mindset (Dweck, 2006). The growth mindset is characterized by embracing challenges, persistence in the face of setbacks, seeing effort as a pathway to mastery, finding lessons in criticism and in others' success. The fixed mindset contrasts the growth mindset with behaviors like avoiding challenges and feedback, defensiveness, giving up too easily, viewing effort as unproductive, and being threatened by others' success. The leaders in this study consistently gave examples that aligned with the growth mindset and they applied this philosophy to their leadership approach. They spoke about ways they sought and accepted opportunities to try new things to stretch their skills, highly valued listening as a practice, and sought feedback to inform improvement. Persistence with a desire to learn and grow are secrets revealed by the leaders in this study.

\section{Implications}

Without research and action around how women are marginalized, the costs to women leaders personally, professionally, and ultimately to institutions will remain unchanged. New research on women working in mostly male workplaces is connecting negative workplace climates to a dysregulated stress response with potentially lasting 
effects. Dysregulated cortisol profiles are linked with poor health outcomes (Taylor \& Manago, 2015). The findings provide evidence of the negative physical and psychological effects of a dominant gender culture. A close examination of institutional culture must be considered to evaluate the success in achieving the community colleges' mission and in measuring progress toward addressing the leadership shortage, but the cost to individuals must also be part of that conversation.

The pressure to perform in a gender-based environment was strong for many of the participants in this study and accepting additional duties was an opportunity to learn new skills. While acquiring new skills is value added, time and workload were also a factor, and the personal cost should be considered. These leaders wanted to learn, are naturally driven but many also questioned their competency and figurative "place at the table." This circumstance raises questions about the messages they receive and the overall balance women leaders are able to achieve and continue on a learning trajectory without exploitation.

Many of the leaders in this study self-disclosed their tendency toward introversion. The top personality traits identified in predicting emerging leaders is conscientiousness, extraversion, and openness to experiences (Judge, Ilies, Bono, \& Gerhardt, 2002). The participants revealed signs of and disclosed indicators that they might rate highly on conscientiousness and openness to experiences but rarely did they identify with the extraversion (being sociable, talkative, outgoing) trait. Extraversion is often emphasized, possibly overemphasized, as an important leadership trait but many of the women in this study did not self-identify in this way and gave examples of the power of listening and its value in effective leadership. Because of their tendency to listen and 
their lack of desire to dominate social situations, introverts are more likely to take in and implement suggestions. In doing so, their followers are more likely to feel empowered and motivated and as a result, be more productive (Cain, 2012). Listening as a leadership behavior is cited as a valued skill in leadership especially for women (Crocker, 2015), and is undervalued in current practice (Simmons, 2011). Listening as a deliberate practice should not be tied so closely to gender nor viewed as a weakness, but acknowledged as a strength in modern leadership and in the evaluation of leadership candidates in the community college.

The AACC's leadership competencies represent a change in direction toward a more transformative leadership process but they are only first steps and more work is needed to deconstruct the underlying cultural forces that threaten to inhibit real change. Missing from this document is a thoughtful examination on the consequences of gender and cultural bias on leadership effectiveness within institutions and beginning steps to mitigate this pernicious force.

\section{Recommendations}

The findings from this study have led me to several recommendations. In the next sections, I articulate my recommendations for further research in both subject and design in the follow section. I offer suggestions to community college for addressing the issue of additional duties as a burden and discuss a strategy to operationalize the AACC's leadership competencies. I also make recommendations for leaders in general to challenge their notions of gender in leadership behaviors. Lastly, I put forward recommendations for current and aspiring women leaders related to mindset, addressing stress, and high personal standards. 


\section{Further Study}

My recommendations for further research include focused research on differences in leadership culture and effectiveness between male and female led institutions. With respect to generational differences or years of service, another aspect to consider is the ways in which junior female leaders experience gender bias compared to their senior female counterparts. Measuring changes in these areas could offer insight into the overall progress toward inclusion of marginalized groups such as women and people of color to more closely align with the goal of the community college to be "the people's college."

Another recommendation is to use explanatory mixed method design to study the effectiveness of the "enable others to act" transformational leadership practice on employee productivity and morale in the community college. The benefit of explanatory mixed method design is the use of both quantitative and qualitative data that can provide a more complete picture of a research problem (Creswell, 2009). Findings from a research study structured in this way could expound upon results from the current study and operationalize some of the strategies used by the women leaders in this study.

\section{Community Colleges}

Community colleges are by nature, a rich environment for new experiences. Many operate like small cities with broad programming that reflect community needs. They can be veritable laboratories for learning well beyond the schedule of classes. Often underfunded and over-assigned community colleges have more work to do than they have resources - a condition that creates opportunities. Having additional duties can and often does play an important role in leadership development of aspiring leaders and institutions; however, they can also represent a burden. To honor and protect this willing 
and capable population, I recommend that institutions formally incorporate exposure to new duties as part of leadership development efforts but do so with a deliberate plan to balance overall responsibilities and workload.

Supplementary work is necessary to determine the effectiveness of strategies to implement leadership competencies as identified by the AACC's Leading Forward initiative. Initial steps to operationalize these ideas could include education and training for Boards of Trustees on how to use the leadership competencies to develop s a rubric for evaluating performance of community college presidents.

\section{Leaders in General}

I recommend to leaders in general and institutions to consider expanded notions of gender in leadership behaviors. For example, I envision a continuum with elaborated ideas of gender on one end and singular concepts (male/female) on the other (Eddy, 2010). This more evolved concept of multidimensional leadership would reward men and women for using an integrated style of leadership. Additionally, incorporating transformational leadership practices such as enable others to act (Kouzes \& Posner, 2003b), hold particular promise in moving toward future visions of leadership in light of the AACC's call for leadership reform. Transformational leadership can become "the motor and transmitter of innovative culture and of the dissemination of knowledge oriented to seeking the best possible performance" (Garcia-Morales, JimenezBarrionuevo, \& Gutierrez-Guitirrez, 2012, p. 1040). The women Vice Presidents of Administrative Services in this study are an experienced and valuable asset in the leadership ranks who are well suited to lead community colleges from this perspective into the future. 


\section{Current and Aspiring Leaders}

I make the following recommendations specifically for women leaders. The results of this study suggest that while women leaders are well qualified with respect to education, experience, drive, and motivation, the effects of a gender-biased culture can negatively impact their sense of belonging and even worthiness. However, I found that the tendency of women leaders is to over-achieve and that most women leaders in this study demonstrated an attitude toward introspection and growth—a powerful combination for success as evidenced by Dweck's (2006) research on the growth mindset. I contend that this information needs to be remembered and celebrated, especially in moments of doubt. There is most definitely a well-deserved "place at the table" for women leaders in the community college.

To reinforce a sense of value and belonging, consider how people are influenced by their own body's nonverbal cues (i.e., thoughts, feelings, and physiology). Women leaders can benefit from the insightful research conducted by Carney, Cuddy, and Yap (2010). Women tend to show fewer postures that communicate non-verbal expressions of power and dominance than men. Carney et.al. found a link between one's nonverbal (e.g., physical posture) and how one governs themselves. It is important for women leaders to note how they hold their physical selves when they feel strong and capable and when they feel weak. This idea is significant because this research shows that bodies can influence minds. Role changes can also influence the body. It is known from other research (Taylor \& Manago, 2015) that women working in male dominated work environments showed higher levels of cortisol (the stress hormone) and that higher cortisol levels have been linked to negative health outcomes. My recommendation is for 
women leaders to monitor their non-verbal body language (and thoughts, feelings) for signs of vulnerability. To reduce cortisol and increase testosterone and risk tolerance, Carney et.al. recommended the power pose or to hold a physical position (e.g. standing with chin up, hands on hips) for two minutes. This easy intervention gives women leaders one way they can affect how they feel and how their bodies respond to stress.

In conclusion, the women leaders in this study placed great value on service to students and the institution, and operating with a high degree of integrity. The AACC's competencies for leadership in the community college are driven by a shift in priorities that emphasize student success and accountability in leadership. The strong alignment between these two should be reaffirming and give confidence to current and aspiring leaders to remain on this path and to push the standard of leadership from this place. 


\section{References}

Aaker, S. (2003). Leadership styles of executive female administrators in Tennessee community colleges. (Unpublished doctoral dissertation, Tennessee State University, TN).

American Association of Community Colleges. (2002). Career paths of community college leaders. Retrieved from http://www.aacc.nche.edu/Publications/Briefs/Documents/06242002careerpaths.p $\mathrm{df}$

American Association of Community Colleges. (2005). Thoughts about leadership. Retrieved from http://www.aacc.nche.edu/newsevents/Events/leadershipsuite/Pages/thoughts.aspx American Association of Community Colleges. (2006). The community college presidency: 2006. Retrieved from:

http://www.aacc.nche.edu/Publications/Briefs/Pages/rb091420071.aspx

American Association of Community Colleges. (2012a). Reclaiming the American dream: A report from the $21^{\text {st }}$ Century Commission on the Future of Community Colleges. Retrieved from http://www.aacc.nche.edu/AboutCC/21stcenturyreport/21stCenturyReport.pdf American Association of Community Colleges. (2012b). Community colleges past to present. Retrieved from http://www.aacc.nche.edu/AboutCC/history/Pages/pasttopresent.aspx American Association of Community Colleges. (2012c). Research brief: Compensation 
and benefits of community college CEO's in 2012. Retrieved from http://www.aacc.nche.edu/AboutCC/Trends/Documents/CEOCompensationResea rchBrief.pdf

American Association of Community Colleges. (2012d). Six competencies for community college leaders. Retrieved from http://www.aacc.nche.edu/newsevents/Events/leadershipsuite/Pages/six_compete ncies.aspx

American Association of Community Colleges. (2013). AACC Competencies for community college leaders second edition. Retrieved from http://www.aacc.nche.edu/newsevents/Events/leadershipsuite/Pages/competencies .aspx

American Association of Community Colleges. (2015). Fast facts from our facts sheet. Retrieved from http://www.aacc.nche.edu/AboutCC/Pages/fastfactsfactsheet.aspx

Amey, M. J., \& VanDerLinden, K. E. (2002). Career paths for community college leaders. American Association of Community Colleges, 2, 1-16.

Amey, M. J., VanDerlinden, K. E., \& Brown, D. F. (2002). Perspectives on community college leadership twenty years in the making. Community College Journal of Research and Practice, 26, 573-589.

Ayman, R. (2004). Situational and contingency approaches to leadership. In J. Antonakis, A. T. Cianciolo, \& R. J. Sternberg (Eds.), The nature of leadership (pp. 148-170). Thousand Oaks, CA: Sage.

Ayman, R., \& Korabik, K. (2010). Leadership: Why gender and culture matter. 
American Psychologist, 65(3), 157-170.

Baglia, B. R., \& Hunt, J. G. (1988). An organizational life cycle approach to leadership. In J. G. Hunt, B. R. Baglia, H. P. Dachler, \& C. A. Schriesheim (Eds.), Emerging leadership vistas, 129-149. Lexington, MA: Health.

Barr, R. B., \& Tagg, J. (1995). From teaching to learning: A new paradigm for undergraduate education. Change, 27(6), 12-25.

Bass, B. M. (1996). A new paradigm of leadership: An inquiry into transformational leadership. Alexandria, VA: U.S. Army Research Institute for the Behavioral Sciences.

Bass, B. M. (1999). Two decades of research and development in transformational leadership. European Journal of Work and Organizational Psychology, 8(1), 932.

Bass, B. M., \& Avolio, B. J. (1995). Multifactor leadership questionnaire. Retrieved from: http://www.mindgarden.com/16-multifactor-leadership-questionnaire.

Belenky, M., Clinchy, B., Goldberger, N., \& Tarule, J. (1986). Women's ways of knowing: The development of self, voice and mind. New York, NY: Basic Books.

Berg, G. (2001). Qualitative research methods for the social sciences. Boston, MA: Allyn \& Bacon.

Bergmann, H., Hurson, K., \& Russ-Eft, D. (1999). Everyone a leader: A grassroots model for the new workplace. New York, NY: John Wily \& Sons.

Bolman, L. G., \& Deal, T. E. (1984). Modern approaches to understanding and managing organizations. San Francisco, CA: Jossey-Bass.

Bolman, L. G., Deal, T. E. (1997). Reframing organizations. San Francisco, CA: Jossey- 
Bass.

Brightharp, C. Y. (1999). Real and ideal leadership practices of women in mid-level administrative positions in student affairs. (Unpublished doctoral Bowling Green State University, Bowling Green, $\mathrm{OH}$ ).

Bryman, A., Bresnen, M., Beardsworth, A., \& Keil, T. (1988). Qualitative research and the study of leadership. Human Relations, 4(1), 13-30.

Burkhart, M. B., (1999). A comparison of leadership style sand organizational cultures of women in two and four year colleges and universities. (Unpublished doctoral, University of Sarasota, FL).

Burns, J. M. (1978). Leadership. New York, NY: Harper Perennial.

Caffarella, R. S. (1992). Psychosocial development of women linkages to teaching and leadership in adult education. Retrieved from ERIC database. (ED354386)

Caffarella, R. S., Clark, M. C., \& Ingram, P. B. (1999). Women in leadership: Living with constraints of the glass ceiling. Initiatives, 59(1), 65-76.

Caffarella, R. S., \& Olson, S. K. (1993). Psychosocial development of women: A critical review of the literature. Adult Education Quarterly, 43(3), 125-151.

Cain, S. (2012) Quiet: The power of introverts in a world that can't stop talking. New York, NY: Crown.

Carney, D. R., Cuddy, A. J. C., Yap, A. J. (2010). Power posing: Brief nonverbal displays affect neuroendocrine levels and risk tolerance. Psychological Science, 21(10), 1363-1368. 
Chliwniak, L. (1997). Higher education leadership: Analyzing the gender gap. Retrieved from ERIC Clearinghouse on Higher Education website: www.ed.gov/databases/ERIC_Digests/ed410846.html

Clark, M. C., Caffarella, R. S., \& Ingram, P. B. (1998). Leadership at the glass ceiling: women's Clark, M.C., experience of mid-management roles. Initiatives, 58(4), 5970.

Cohen, A., \& Florence, B. (1996). The American community college. San Francisco, CA: Jossey-Bass.

Creswell, J. W. (2005). Educational research: Planning, conducting, and evaluating quantitative and qualitative research ( $2^{\text {nd }}$ ed.). Columbus, OH: Pearson Merrill Prentice Hall.

Creswell, J.W. (2007). Qualitative inquiry \& research design ( $2^{\text {nd }}$ ed.). Thousand Oaks, CA: Sage.

Creswell, J. W. (2009). Research design: Qualitative, quantitative, and mixed methods approaches (3rd. ed.). Thousand Oaks, CA: Sage.

Crocker, R. (2015). The heroine's journey: Women and leadership. Canadian Manager, $39(4), 20-21$.

Curry, B. K. (2000). Women in power: Pathways to leadership in Education. New York, NY: Teachers College Press.

Day, V. D., \& Antonakis, J. (2012). The Nature of Leadership (2 ${ }^{\text {nd }}$ ed.). Thousand Oaks, CA: Sage.

Delta Cost Project. (2009). Trends in college spending. Retrieved from http://deltacostproject.org/resources/pdf/trends_in_spending-report.pdf 
DiCroce, D. M. (1995). Women and the community college presidency: Challenges and possibilities. In B. K. Townsend (Ed.), Gender and power in the community college: New directions for community colleges (p. 79-88). San Francisco, CA: Jossey-Bass.

Dweck, C. S. (2006). Mindset: The new psychology of success. New York, NY: Random House.

Eagly, A. H. (1991). Gender and leadership. Journal of Personality and Social Psychology, 60(5), 685-710.

Eagly, A. H., \& Johannesen-Schmidt, M. C. (2001). The leadership styles of women and men. Journal of Social Issues, 57, 781-797.

Eagly, A., Johannesen-Schmidt, M., \& Van Engen, M. (2003). Transformational, transactional, and laissez-faire leadership styles. Retrieved from http://www.sozialpsychologie.uni-frankfurt.de/wpcontent/uploads/2011/10/Eagly-et-al_2003.pdf

Eddy, P. L. (2010). Community college leadership: A multidimensional model for leading change. Sterling, VA: Stylus.

Elias, D. (1991). Educating leaders for social transformation. (Unpublished doctoral Dissertation, Columbia University, NY).

Evelyn, J. (2001, April 6). Community colleges face a crisis in leadership. The Chronicle of Higher Education, p. A36.

Fairhurst, G. T., \& Sarr R. A. (1996). The art of framing: Managing the language of leadership. San Francisco, CA: Jossey-Bass.

Fiedler, F. E. (1967). A theory of leadership effectiveness. New York: NY. McGraw Hill. 
Flynn, W. J. (2006). The search for the learning-centered college. Retrieved from http://www.aacc.nche.edu/Resources/aaccprograms/pastprojects/Pages/searchforl earning.aspx

Fowler, F. J. (2009). Survey research methods (4 ${ }^{\text {th }}$ ed.). Thousand Oaks, CA: Sage.

Garcia-Morales, V. J., Jimenez-Barrionuevo, M. M., Gutierrez-Gutierrez, L. (2012). Transformational leadership influence on organizational performance through organizational learning and innovation. Journal of Business Research, 65, 10401050.

Gardner, W. L., Lowe, K. B., Moss, T. W., Mahoney, K.T., \& Cogliser, C. C. (2010). Scholarly leadership of the study of leadership: A review of the leadership quarterly's second decade, 2000-2009. The Leadership Quarterly, 21, 992-958.

Gilligan, C. (1993). In a different voice. Cambridge, MA: Harvard University Press. Glazer-Raymo, J. (1999). Shattering the myths: Women in academe. Baltimore, MD: The Peters Hopkins University Press.

Goff, D. G. (2003). What do we know about good community college leaders: A study in leadership trait theory and behavioral leadership theory. Retrieved from http://www.eric.ed.gov/contentdelivery/servlet/ERICServlet?accno=ED476456 00000aacb361\&acdnat=1352660180_58274f188a39a834f048266e1a3a3d8a

Goldberger, N., Tarule, J., Clinchy, B., \& Belenky, M. (1996). Knowledge, difference, and power. New York, NY: Basic Books.

Gorenflo, B. A. (1994). Shared characteristics of effective women administrators at 
Eastern Michigan University and Wayne State University. (Unpublished master's thesis, Eastern Michigan University, Ypsilanti, MI).

Graham, J. W. (1991). Servant-leadership in organizations: Inspirations and moral. Leadership Quarterly, 2(2), 105-119.

Haley, M. H. (2001). Refocusing the lens: A closer look at universities in the new millennium. Multicultural Education, 9(2), 21-23.

Hall, J., Johnson, S., Wysocki, A., \& Kepner, K., 2002. Transformational leadership: The transformation of managers and associates. Retrieved from http://edis.ifas.ufl.edu/pdffiles/HR/HR02000.pdf

Halpin, A. W. (1957). Manual for the Leadership Behavior Description Questionnaire. Retrieved from http://fisher.osu.edu/supplements/10/2862/1957\%20LBDQ\%20MANUAL.pdf

Hannah, S. T., Uhl-Bien, M., Avolio, B. J., \& Cavaretta, F. L. (2009). A framework for examining leadership in extreme contexts. The Leadership Quarterly, 20, 897919.

Hayes, E., \& Flannery, D. (2000). Women as learners: The significance of gender in adult learning. San Francisco, CA: Jossey-Bass.

Helgesen, S. (1990). The female advantage: Women's ways of leadership. New York, NY: Doubleday.

Hemphill, J. K., \& Coons, A. E. (1957). Development of the Leader Behavior Description Questionnaire. In R. M. Stogdill \& A. E. Coons (Eds.), Leader behavior: Its description and measurement (pp. 6-38). Columbus, OH: Ohio State University. 
Hibbing, J. R., \& Theiss-Morse, E. (2002). Stealth democracy: American's beliefs about how government should work. New York, NY: Cambridge University Press.

Jablonski, M. (1996). The leadership challenge for women college presidents. Initiatives, 7(4), 1-10.

Joliet Junior College. (n.d.). Joliet Junior College History. Retrieved fromhttp://www.jjc.edu/about/pages/default.aspx.

Judge, T. A., Ilies, R., Bono, J. E., \& Gerhardt, M. W. (2002). Personality and leadership: A qualitative and quantitative review. Journal of Applied Psychology, 87(4), 765780.

Kampel, D. (2010). Learning leadership: Women presidents of colleges and universities. Saarbrücken, Germany: LAP Lambert Academic.

Kanter, R. (1997). Rosabeth Moss Kanter on the frontiers of management. Boston, MA: Harvard Business School Press.

Katsinas, S. G., Tollefson, T. A., Reamey, B. A. (2008). Funding issues in U.S. Community Colleges: Findings from a 2007 survey of the national state directors of community colleges. Retrieved from http://www.aacc.nche.edu/Publications/Reports/Documents/fundingissues.pdf

Kellerman, B., \& Rhode, D. (2007). Women and leadership: The state of play and strategies for change. San Francisco, CA: Jossey-Bass.

Kennedy, J. F. (1963). Undelivered remarks for Dallas Citizens Council, Trade Mart, Dallas, Texas, 22 November 1963. Retrieved from http://www.jfklibrary.org/Asset-Viewer/Archives/JFKPOF-048-022.aspx.

Kershaw, T. S., \& Alexander, S. (2003). Procedural fairness, blame attributions, and 
Presidential leadership. Social Justice Research, 16(1), 79-93.

King, M. L., \& Washington, J. M. (1986). A testament of hope: The essential writings of Martin Luther King, Jr. San Fransisco, CA: Harper \& Row.

Knowles, M. S. (1980). The modern practice of adult education: From pedagogy to andragogy. New York, NY: Cambridge Books.

Kohlberg, L. (1969). The development of modes of thinking and choices in years 10 to 16. Doctoral dissertation, University of Chicago, 1958.

Kouzes, J. M., \& Posner, B. Z. (1987). The leadership challenge. San Francisco, CA: Jossey-Bass.

Kouzes, J. M., \& Posner, B. Z. (1995). The leadership challenge: How to keep getting extraordinary things done in organizations. San Francisco, CA: Jossey-Bass.

Kouzes, J. M., \& Posner, B. Z. (2002). The Leadership Practices Inventory: Theory and evidence behind the five practices of exemplary leaders. Retrieved from The Leadership Challenge website: http://media.wiley.com/assets/463/74/lc_jb_appendix.pdf

Kouzes, J. M., \& Posner, B. Z. (2003a). Leadership Practices Inventory (3 ${ }^{\text {rd }}$ ed.) Retrieved from: http://www.pfeiffer.com/WileyCDA/Section/id-811879.html=.

Kouzes, J. M., \& Posner, B. Z., (2003b). Leadership Practices Inventory ( $3^{\text {rd }}$ ed.): Psychometric properties. Retrieved from http://www.leadershipchallenge.com/UserFiles/lc_jb_psychometric_properti.pdf

Kouzes, J. M., \& Posner, B. Z, (2003c). Leadership practices inventory: Leadership development planner ( $3^{\text {rd }}$ ed.). San Francisco, CA. Pfeiffer. 
Kouzes, J. M., \& Posner, B. Z. (2007). The leadership challenge (4 ${ }^{\text {th }}$ ed.). San Francisco, CA: Jossey-Bass.

League for Innovation in the Community College. (1995). The Learning College Project. Retrieved from http://www.league.org/league/projects/lcp/index.htm

Lipman-Blumen, J. (1996). The connective edge: Leading in an interdependent world. San Francisco, CA: Jossey-Bass.

Liden, R. C., \& Antonakis, J. (2009). Considering context in psychological leadership research. Human Relations, 62(11), 1587-1605.

Lofstrom, E., \& Nevgi, A. (2007). From strategic planning to meaningful learning: Diverse perspectives on the development of web-based teaching and learning in higher education. British Journal of Educational Technology, 38(2), 312-324.

Lucey, C. A. (2002). Civic engagement, shared governance, and community colleges. Academe, 4(88), 27-31.

Maher, F., \& Tetreault, M. (1994). The feminist classroom. New York, NY: Basic Books. Merriam, S. B. (2009). Qualitative research: A guide to design and implementation. San Franscisco, CA: Jossey-Bass.

Merriam, S. B., \& Caffarella, R. S. (1999). Learning in adulthood: A comprehensive guide. San Francisco, CA: Jossey-Bass.

Michigan Studies. (n.d.). Retrieved from http://changingminds.org/disciplines/leadership/actions/michigan.htm Miner, J. B. (1993). Role motivation theories. New York, NY: Routledge. Mintzberg, H. (1973). The nature of managerial work. New York, NY: Harper \& Row. 
Moore, D. R., \& Burton, J. K. (1998). The new media centers' consortium: A tool for legitimizing technology in higher education. Journal of Research on Computing in Education, 3(30) 296-306.

Noddings, N. (1984). A feminine approach to ethics and moral education. Berkeley, CA: University of California Press.

Oakley, A. (1981). Interviewing women: A contradiction in terms. In H. Roberts (Ed.), Doing feminist research (pp. 31-49). London, England: Routledge \& Kegan Paul Books.

Ottinger, D. C. (1990). Differences in leadership practices and selected demographic characteristics of women executives in the top three positions of higher education and banking. (Unpublished doctoral dissertation, Bowling Green State University, Bowling Green, $\mathrm{OH})$.

Outcalt, C. L. (2002). Special issue: Community college faculty: Characteristics, practices, and challenges. [Electronic version]. New Directions for Community Colleges, 118, 69-78.

Patton, M.Q. (1990). Qualitative evaluation and research methods (2 ${ }^{\text {nd }}$ ed.). Newbury Park, CA: Sage.

Phillippe, K. (2000). Profile of community colleges: Trends and statistics ( $3^{\text {rd }}$ ed.). Washington, DC: Community College Press.

Rosener, J. (1990). Ways women lead. Harvard Business Review, 6(68), 119-125. Rost, J. C. (1993). Leadership for the twenty-first century. Westport, CT: Prega. 
Ryan, R. M., \& Delci, E. M. (2000). Intrinsic and extrinsic motivations: Classic definitions and new directions. Contemporary Educational Psychology, 25, 5467.

Schein, E. H. (1980). Organizational psychology (3 rd ed.). Upper Saddle River, NJ: Prentice Hall.

Schein, E. H. (1990). Organizational culture and leadership. San Francisco, CA: JosseyBass.

Schein, E. H. (2000). Commentary: Sense and nonsense about culture and climate. In N. M. Ashkanasy, C. P. M. Wilderom, \& M. F. Peterson (Eds.), Handbook of organizational culture and climate (pp.79-84). Thousand Oaks, CA: Sage.

Schein, V. E. (1973). The relationship between sex role stereotypes and requisite management characteristics. The Journal of Applied Psychology, 57(2), 95-100.

Schein, V. E. (2001). A global look at psychological barriers to women's progress in management. Journal of Social Issues, 57, 675-688.

Sczesny, S., Bosak, J., Neff, D., \& Schyns, B. (2004). Gender stereotypes and the attribution of leadership traits: A cross-cultural comparison. Sex Roles, 51, 631645.

Short, P. M., \& Greer, J. T. (2002). Leadership in empowered schools: Themes from innovative efforts ( $2^{\text {nd }}$ ed.). Upper Saddle River, NJ: Merrill Prentice Hall.

Simmons, A. (2002). The story factor. New York, NY: Basic books.

Simmons, R. (2011). Leadership and listening: The reception of user voice in today's public service. Social Policy and Administration, 45, 5, 539-568. 
Stake, R. E. (2005). Qualitative case studies. In N.K. Denzin \& Y.S. Lincoln (Eds), Sage handbook of qualitative research (3red ed., pp. 443-466). Thousand Oaks, CA: Sage.

Stogdill, R. M. (1948). Personal factors associated with leadership: A survey of the literature. Journal of Psychology, 25, 35-71.

Stodgill, R. M., (1963). Manual for the Leadership Behavior Questionnaire-form XII: An experimental revision. Retrieved from https://cyfernetsearch.org/sites/default/files/LBDQ_1962_MANUAL_SCORING. pdf.

Stone, D. (1997). Policy paradox. New York, NY: W. W. Norton.

Tarule, J. M. (1988). Voices of returning women: ways of knowing. New Directions for Continuing Education, 39, 19-31.

Taylor, C. \& Manago, B. (2015). Women in mostly male workplaces exhibit psychology stress response. Retrieved from http://www.eurekalert.org/pub_releases/201508/iu-wim082215.php

Taylor, T. A. (2002). Examination of leadership practices of principals identified as servant leaders. (Unpublished doctoral dissertation, University of Missouri Columbia, MO).

Tedrow, B., \& Rhoads, R. A. (1998, November). Senior women community college administrators: Life in education's inner circle [Electronic version]. Paper presented at the annual meeting of the Association for the Study of Higher Education, Miami, FL. (ERIC Clearinghouse ED427614).

Tedrow, B., \& Rhoads, R. A. (1999). A qualitative study of women's experiences in 
community college leadership positions. Community College Review, 27(3), 1-18.

Townsend, B. K. (2009). Community college organizational climate for minorities and women. Community College Journal of Research and Practice, 33(9), 731-744.

Townsend, B. K., \& Twombly, S. B. (1998). A feminist critique of organizational change in the community college. New Directions for Community Colleges, 102, 77-85.

Townsend, B. K., \& Twombly, S. B. (2007). Accidental equity: The status of women in the community college. Equity \& Excellence in Education, 40(3), 208-217.

Tyler, T. R., \& Blader, S. (2005). Can businesses effectively regulate employee conduct? The antecedents of rule following in work settings. Academy of Management Journal, 48(6), 1143-1158.

Useem, A. (2009, February 12). The ten best leadership books of all time. The Washington Post. Retrieved from http://views.washingtonpost.com/leadership/leadership_playlist/2009/02/the-10best-leadership-books-of-all-time.html

Valdata, P. (2006). Lonely at the top? Diverse: Issues in Higher Education, 23(20), 2835.

Washington State Board for Community and Technical Colleges. (2015a). Creating opportunities for Washington's future. Retrieved from http://www.sbctc.ctc.edu/general/a_systemdirection.aspx

Washington State Board for Community and Technical Colleges (2015b). About the community and technical colleges. Retrieved from http://www.sbctc.ctc.edu/public/a_index.aspx

Wiersma, W. (2000). Research methods in education: An introduction. Boston, MA: 
Allyn \& Bacon.

Williams, J. E., \& Best, D. L. (1990). Measuring sex stereotypes: A multination study. Newbury Park, CA: Sage.

Williams, T. E. (2002). Challenges in supporting student learning and success through student services. New Directions for Community Colleges, 117, 67-76.

Yoder, J. D. (2001). Making leadership work more effectively for women. Journal of Social Issues, 57, 815-828.

Young, P. (2004). Leadership and gender in higher education: a case study. Journal of Further and Higher Education, 28(1), 95-106.

Yukl, G. (1991). An evaluation of conceptual weaknesses in transformational and charismatic leadership theories. Leadership Quarterly, 10(2), 285-305.

Zaccaro, S. J. (2007). Trait-based perspectives of leadership. American Psychologist, 62(1), 6-16. 


\section{Appendix A}

\section{Informed Consent}

Title of Research Study: Leadership Experiences of Women Administrative Vice Presidents in Community Colleges: A Qualitative Study

You are invited to participate in a research study conducted by Jennifer Grove-Heuser from Portland State University, Graduation School of Education, Curriculum and Instruction. The researcher intends to learn: (a) how women experience leadership in the community college, (b) how do women exhibit leadership practices, and (c) how women learned to lead. This study is being conducted in partial fulfillment of the requirements for a doctoral degree, and is under the supervision of Micki M. Caskey, Ph.D., Professor, Portland State University.

You were selected as a possible participant for this study because you are a woman, currently serving as a Vice President of Administrative Services in a NW community college. If you decide to participate, you will engage in an in-person or phone interview lasting 60 to 90 minutes in a location according to your convenience. For the purpose of accuracy and consistency, the interview will be digitally recorded and transcribed. A short follow up survey will be offered to you to assess leadership practices; the results of this survey will be provided to you. You will be asked to recall events, activities, and feelings about past leadership and professional experiences. If at any time, these questions or inquiry process is uncomfortable or otherwise unacceptable you can withdraw from participation. You may not receive any direct benefit from taking part in this study; however, the study may advance knowledge that may help other women leaders and institutions in the future.

Any information that is obtained in connection with this study and that can be linked to you or identify you will be kept confidential. This information will be kept confidential by securing all data collected electronically.

Your participation is voluntary. You do not have to take part in this study, and it will not affect your relationship with Portland State University. You may also withdraw from this study at any time without affecting your relationship with Portland State University.

If you have concerns or problems about your participation in this study or your rights as a research subject, please contact the Human Subjects Research Review Committee, Office of Research and Sponsored Projects, Portland State University, 503-725-4288/1-877-480-4400. If you have questions about the study itself, contact Jennifer Grove-Heuser at 503-957-9824, groveje@gmail.com or her doctoral advisor, Micki M. Caskey at caskeym@pdx.edu.

Your signature indicates that you have read and understand the above information and agree to take part in this study. Please understand that you may withdraw your consent at any time without penalty, and that, by signing, you are not waiving any legal claims, rights or remedies. The researcher will provide you with a copy of this form for your own records. 


\section{Appendix B}

\section{Women Administrative Vice Presidents Demographic Survey}

1. What is your current title?

2. In which department is your current position?

3. What leadership positions have you held and for how long?

4. How many years of leadership experience do you have?

5. What is your highest degree earned and in which specialization?

6. Did you received specialized leadership training, if so, please describe?

7. What is your race/ethnicity?

NAME:

Thank you for your participation and support of research in women's leadership. 


\section{Appendix C}

\section{Women Administrative Vice President Interview Questions}

1. Please describe your professional background.

Probes: leadership positions, title, responsibilities, skill building, follow up from demographic survey

2. What experiences have impacted your leadership behaviors?

Please describe the impact.

3. Why did you decide to seek your first leadership position?

4. What leadership practices are most important to you?

5. What experiences have best supported you in learning to lead?

6. How has your identity as a woman and your professional identity come together?

7. Describe how your values affect your actions as a leader.

8. Describe how the organizational culture has impacted your experience as a leader.

Probes: positive/negative examples, challenges, and opportunities

9. What are the most fulfilling aspects of your work?

10. What is next for you in your career?

11. How would you advise other women seeking an executive leadership position? 


\section{Appendix D}

\section{Kouzes \& Posner's Leadership Practices Inventory, SELF}

\section{$\mathbf{L P} \mathbf{i}_{\text {sELF }}$ \\ Leadership Practices Inventory}

by JAMES M. KOUZES

\& BARRY Z. POSNER

\section{INSTRUCTIONS}

Write your name in the space provided at the top of the next page. Below your name, you will find thirty statements describing various leadership behaviors. Please read each statement carefully, and using the RATING SCALE on the right, ask yourself:

\section{"How frequently do I engage in} the behavior described?"

- Be realistic about the extent to which you actually engage in the behavior.

- Be as honest and accurate as you can be.

- DO NOT answer in terms of how you would like to behave or in terms of how you think you should behave

- DO answer in terms of how you typically behave on most days, on most projects, and with most people.

- Be thoughtful about your responses. For example, giving yourself 10 s on all items is most likely not an accurate description of your behavior. Similarly, giving yourself all $1 \mathrm{~s}$ or all $5 \mathrm{~s}$ is most likely not an accurate description either. Most people will do some things more or less often than they do other things.

- If you feel that a statement does not apply to you, it's probably because you don't frequently engage in the behavior. In that case, assign a rating of 3 or lower.

For each statement, decide on a response and then record the corresponding number in the box to the right of the statement. After you have responded to all thirty statements, go back through the LPI one more time to make sure you have responded to each statement. Every statement must have a rating.
The RATING SCALE runs from 1 to 10 . Choose the number that best applies to each statement.

$\left[\begin{array}{rl}1 & =\text { Almost Never } \\ 2 & =\text { Rarely } \\ 3 & =\text { Seldom } \\ 4 & =\text { Once in a While } \\ 5 & =\text { Occasionally } \\ 6 & =\text { Sometimes } \\ 7 & =\text { Fairly Often } \\ 8 & =\text { Usually } \\ 9 & =\text { Very Frequently } \\ 10 & =\text { Almost Always }\end{array}\right]$

When you have completed the LPI-Self, please return it to:

Thank you. 


\section{Your Name:}

To what extent do you typically engage in the following behaviors? Choose the response number that best applies to each statement and record it in the box to the right of that statement.

1. I set a personal example of what I expect of others.

2. I talk about future trends that will influence how our work gets done.

3. I seek out challenging opportunities that test my own skills and abilities.

4. I develop cooperative relationships among the people I work with.

5. I praise people for a job well done.

6. I spend time and energy making certain that the people I work with adhere to the principles and standards we have agreed on.

7. I describe a compelling image of what our future could be like.

8. I challenge people to try out new and innovative ways to do their work.

9. I actively listen to diverse points of view.

10. I make it a point to let people know about my confidence in their abilities.

11. I follow through on the promises and commitments that I make.

12. I appeal to others to share an exciting dream of the future.

13. I search outside the formal boundaries of my organization for innovative ways to improve what we do.

14. I treat others with dignity and respect.

15. I make sure that people are creatively rewarded for their contributions to the success of our projects.

16. I ask for feedback on how my actions affect other people's performance.

17. I show others how their long-term interests can be realized by enlisting in a common vision.

18. I ask "What can we learn?" when things don't go as expected.

19. I support the decisions that people make on their own.

20. I publicly recognize people who exemplify commitment to shared values.

21. I build consensus around a common set of values for running our organization.

22. I paint the "big picture" of what we aspire to accomplish.

23. I make certain that we set achievable goals, make concrete plans, and establish measurable milestones for the projects and programs that we work on.

24. I give people a great deal of freedom and choice in deciding how to do their work.

25. I find ways to celebrate accomplishments.

26. I am clear about my philosophy of leadership.

27. I speak with genuine conviction about the higher meaning and purpose of our work.

28. I experiment and take risks, even when there is a chance of failure.

29. I ensure that people grow in their jobs by learning new skills and developing themselves.

30. I give the members of the team lots of appreciation and support for their contributions. $\square$ $\square$ $\square$ $\square$ $\square$ 